\title{
The spinal microglial IL-10/ $\beta$-endorphin pathway accounts for cinobufagin-induced mechanical antiallodynia in bone cancer pain following activation of a7-nicotinic acetylcholine receptors
}

Evhy Apryani, Usman Ali, Zi-Ying Wang, Hai-Yun Wu, Xiao-Fang Mao, Khalil Ali Ahmad, Xin-Yan Li and Yong-Xiang Wang ${ }^{*}$ (D)

\begin{abstract}
Background: Cinobufagin is the major bufadienolide of Bufonis venenum (Chansu), which has been traditionally used for the treatment of chronic pain especially cancer pain. The current study aimed to evaluate its antinociceptive effects in bone cancer pain and explore the underlying mechanisms.

Methods: Rat bone cancer model was used in this study. The withdrawal threshold evoked by stimulation of the hindpaw was determined using a 2290 CE electrical von Frey hair. The $\beta$-endorphin and IL-10 levels were measured in the spinal cord and cultured primary microglia, astrocytes, and neurons.

Results: Cinobufagin, given intrathecally, dose-dependently attenuated mechanical allodynia in bone cancer pain rats, with the projected $E_{\max }$ of $90 \% \mathrm{MPE}$ and $\mathrm{ED}_{50}$ of $6.4 \mathrm{\mu g}$. Intrathecal cinobufagin also stimulated the gene and protein expression of IL-10 and $\beta$-endorphin (but not dynorphin A) in the spinal cords of bone cancer pain rats. In addition, treatment with cinobufagin in cultured primary spinal microglia but not astrocytes or neurons stimulated the mRNA and protein expression of IL-10 and $\beta$-endorphin, which was prevented by the pretreatment with the IL10 antibody but not $\beta$-endorphin antiserum. Furthermore, spinal cinobufagin-induced mechanical antiallodynia was inhibited by the pretreatment with intrathecal injection of the microglial inhibitor minocycline, IL-10 antibody, $\beta$ endorphin antiserum and specific $\mu$-opioid receptor antagonist CTAP. Lastly, cinobufagin- and the specific a-7 nicotinic acetylcholine receptor (a7-nAChR) agonist PHA-543613-induced microglial gene expression of IL-10/ $\beta$ endorphin and mechanical antiallodynia in bone cancer pain were blocked by the pretreatment with the specific a7-nAChR antagonist methyllycaconitine.
\end{abstract}

Conclusions: Our results illustrate that cinobufagin produces mechanical antiallodynia in bone cancer pain through spinal microglial expression of IL-10 and subsequent $\beta$-endorphin following activation of a7-nAChRs. Our results also highlight the broad significance of the recently uncovered spinal microglial IL-10/ $\beta$-endorphin pathway in antinociception.

Keywords: Cinobufagin, Microglia, IL-10/ß-endorphin pathway, a7-nicotinic acetylcholine receptor (a7-nAChR)

\footnotetext{
* Correspondence: lixy@sjtu.edu.cn; yxwang@sjtu.edu.cn

Shanghai Jiao Tong University School of Pharmacy, 800 Dongchuan Road,

Shanghai 200240, China
}

(c) The Author(s). 2020 Open Access This article is distributed under the terms of the Creative Commons Attribution 4.0 International License (http://creativecommons.org/licenses/by/4.0/), which permits unrestricted use, distribution, and

reproduction in any medium, provided you give appropriate credit to the original author(s) and the source, provide a link to the Creative Commons license, and indicate if changes were made. The Creative Commons Public Domain Dedication waiver (http://creativecommons.org/publicdomain/zero/1.0/) applies to the data made available in this article, unless otherwise stated. 


\section{Introduction}

Bufonis venenum (Chansu) is a traditional Chinese medicine that is prepared from the dried white secretion of the auricular glands and the skin glands of Bufo gargarizans Cantor or Bufo melanostictus Schneider. Being listed in the Chinese Pharmacopeia, Bufonis venenum has been used as a therapeutic agent in Asian countries for centuries to treat cardiovascular diseases, inflammatory diseases, cancers and chronic pain [12, 70, 80, 87, 88, 91]. The major active components in Bufonis venenum are bufadienolides, such as cinobufagin, bufalin, resibufogenin, cinobufotalin, bufotenine, bufotenidine, and bufobutanoicacid, the first three of which account for approximately $10 \%$ of the dry weight of toad venom [43, 46, 47, 84, 86]. The antiinflammatory and antinociceptive effects of Bufonis venenum and its purified bufadienolides have been extensively studied over the past years. Gavage and intraperitoneal administration of Bufonis venenum, cinobufagin and bufalin produced marked antinociception in the hot-plate, formalin and acetic acid writing tests [74, 81, 82]. Interestingly, Bufonis venenum has remarkable analgesic effect in patients with cancer pain including that from bone metastasis [22, 50], while it has been also served as an antitumor agent $[2,12,25,48]$. Preclinical studies showed that multiple daily intraperitoneal injections of Bufonis venenum (referred as to cinobufagin in the original paper) exerted mechanical antiallodynia and thermal antihyperalgesia in a mouse model of paw cancer pain $[9,10]$.

However, the mechanisms underlying Bufonis venenum- and its effective ingredients-induced analgesia especially in cancer pain remain unclear. It was postulated that Bufonis venenum produced antinociception through inhibition of neuronal adenosine triphosphatase sodiumpotassium pump or $\mathrm{Na}^{+}-\mathrm{K}^{+}$ATPase [72], as its effective ingredients bufadienolides are a group of steroid hormones, which, like ouabain, inhibit $\mathrm{Na}^{+}-\mathrm{K}^{+}$ATPase $[11,17,18,41]$ leading to antinociception [15, 68]. Also, it was recently proposed that cinobufagin exerted antinociception via activation of the $\alpha-7$ nicotinic acetylcholine receptor $(\alpha 7-\mathrm{nAChR})$, since cinobufagin antinociception in the hot-plate, formalin and acetic acid writing tests were reversed by intraperitoneal administration of the specific $\alpha 7-n A C h R$ antagonist methyllycaconitine and intrathecal injection of the $\alpha 7$ nAChR gene silencer siRNA/ $\alpha 7-n A C h R$ [82]. The $\alpha 7-$ $\mathrm{nAChR}$, which is expressed in glial cells and closely associated with inhibition of neuroinflammation, is a potential target molecule for the treatment of chronic pain $[1,14,27,38,62]$.

It is also controversial whether the inhibition of the proinflammatory cytokine expression or stimulation of the opioid peptide expression is responsible for Bufonis venenum or its effective ingredients-induced antinociception. Treatment with cinobufagin in human monocyte-derived dendritic cells potently inhibited LPS-induced maturation and production of proinflammatory cytokines including interleukin (IL)-1 $\beta$, IL-6, and tumor necrosis factor (TNF)- $\alpha$ [80]. Intraperitoneal injection of bufalin also reduced carrageenan-induced edema, and inhibited NF- $\mathrm{B}$ activation and downregulated the expression of inducible nitric oxide synthase, cyclooxygenase-2, IL-1 $\beta$, IL- 6 , and TNF- $\alpha$ in the carrageenan-injected paw tissues [74]. In addition, cinobufagin injection in the dorsal root ganglion inhibited NF- $\mathrm{kB}$ activation and proinflammatory cytokine expression [82]. These findings suggested that Bufonis venenum induced antinociception via inhibition of NF- $\mathrm{kB}$ activation and subsequent expression of inflammatory cytokines [74, 80, 82]. However, administration of Bufonis venenum promoted the $\beta$-endorphin and corticotropin-releasing factor (CRF) levels in plasma, and immunostaining of $\beta$-endorphin and $\mu$ opioid receptors in the tumor xenograft tissues of paw cancer pain mice; treatment with Bufonis venenum also stimulated the expression of $\beta$-endorphin and CRF in cultured primary lymphocytes $[9,10]$. Moreover, the antinociceptive effect of Bufonis venenum or bufalin was blocked by the pretreatment with the opioid receptor antagonist naloxone or its peripheral form naloxone methiodide $[9,10,74]$. These studies suggested that Bufonis venenum and its effective ingredients produced antinociception through the $\beta$-endorphin/opioid receptor pathway $[9,10]$.

Cinobufagin is probably the most abundant bufadienolide in Bufonis venenum and has displayed significant analgesic effect [35, 43, 46, 47, 84, 86]. Therefore, it was selected in this study to evaluate the antinociceptive effects of Bufonis venenum in cancer pain and explore the underlying mechanisms. We recently discovered that microgliaderived IL-10 in neuropathic pain produced mechanical antiallodynia and thermal antihyperalgesia via autocrine secretion of $\beta$-endorphin which interacted with neuronal $\mu$ opioid receptors [77, 78]. Futhermore, we also uncovered that the glucagon-like peptide-1 (GLP-1) receptor agonist exenatide and GPR40 agonist GW9508 produced mechanical antiallodynia and thermal antihyperalgesia in neuropathic rats through autocrine glial secretion of IL-10 and subsequent $\beta$-endorphin $[52,79]$. Thus, we postulated that cinobufagin may produce antinociception by triggering the microglial IL-10/ $\beta$-endorphin pathway after activation of $\alpha 7-n A C h R s$. We first established the rat model of bone cancer pain and assessed the mechanical antiallodynic effect of cinobufagin given intrathecally. We then observed the stimulatory effects of cinobufagin on the expression of IL-10 and subsequent $\beta$-endorphin in the spinal cords of bone cancer rats and cultured spinal primary microglial cells. Furthermore, we attempted to illustrate whether spinal microglial expression of IL-10/ $\beta$-endorphin was causally associated with cinobufagin-induced mechanical antiallodynia. Lastly, we tested whether cinobufagin- 
induced microglial IL-10/ $\beta$-endorphin expression and mechanical antiallodynia were $\alpha 7$-nAChR-dependent.

\section{Materials and methods Drugs and reagents}

Cinobufagin was purchased from ChemFaces (Wuhan, Hubei, China) with $\geq 98 \%$ purity determined by ${ }^{1} \mathrm{H}-\mathrm{NMR}$, and SP600125, SB203580 and U0126 were obtained from Selleck Chemicals (Houston, TX, USA). PHA-543613, ouabain octahydrate, and methyllycaconitine citrate were obtained from Sigma-Aldrich (St. Louis, MO), Acros Organics (NJ, USA) and ApexBio (Shanghai, China), while minocycline and CTAP were purchased from Yuanye Biotech (Shanghai, China) and Tocris (Bristol, UK), respectively. $\alpha$-Helical CRF (9-41) was synthesized with the peptide contents of 98\% in Shanghai TASH Biotechnology Co. (Shanghai, China). The rabbit $\beta$-endorphin antiserum and recombinant rat IL-10 antibody were purchased from Abcam (Cambridge, UK) and PeproTech (NJ, USA), respectively. Cinobufagin was dissolved in 10\% dimethyl sulfoxide (DMSO) and 20\% polyethylene glycol (PEG400) in $0.9 \%$ normal saline for intrathecal injection and in $0.1 \%$ DMSO for cell culture. $\alpha$-Helical CRF (9-41) was dissolved in 30\% DMSO and 70\% PEG400. All other drugs or reagents were dissolved in normal saline.

\section{Animals}

Male or female neonatal ( 1 day old) and adult (8-10 weeks old) Wistar rats were purchased from the Shanghai Experimental Animal Institute for Biological Sciences (Shanghai, China). The adult rats were housed in the plastic cages in the animal room with temperature- and humidity-controlled environment on a 12-h-light/dark cycle and acclimatized to the laboratory environment for 2-3 days prior to experiments, with food and water ad libitum. The animal procedure protocols were approved by the Animal Care and Welfare Committee of the Shanghai Jiao Tong University (Shanghai, China) and followed the regulatory animal care guidelines of the US National Institutes of Health.

\section{Rat model of bone cancer pain}

The rat bone cancer pain model was induced as described previously [24, 31]. Walker 256 carcinoma cells $\left(4 \times 10^{5}\right)$ in $10 \mu \mathrm{L}$ of the phosphate buffer solution were implanted directly into the tibia cavity of female or male anesthetized rats using a $10-\mu \mathrm{L}$ microinjection syringe. The injection site was sealed using the aseptic bone wax to prevent the spreading of the carcinoma cells to the surrounding soft tissue. The wound was covered with the penicillin powder and closed. After recovery from the inoculation surgery and anesthesia, the rats were returned to their home cages.

\section{Intrathecal injection}

The direct intrathecal injection was performed by holding the rat securely in one hand by the pelvic girdle and inserting a 25 -gauge $\times 1$ in. needle, connected to a $25-\mu \mathrm{L}$ Hamilton syringe, into the tissues between the dorsal aspects of L5 and L6, perpendicular to the vertebral column. The tip of the needle was kept at the injection site for approximately $15 \mathrm{~s}$ to ensure the delivery of the solution. The quality of each injection was ensured by the observation of an injection-induced tail-flick [53]. The method was validated by using the lidocaine paralysis method [52] and extensively practiced in house.

\section{Behavioral assessment of mechanical allodynia}

The assessment of withdrawal thresholds in the contralateral and ipsilateral hindlimbs of bone cancer pain rats was conducted approximately 3 weeks after the inoculation of Walker 256 carcinoma cells surgery as described by Wu et al. $[77,78]$. Bone cancer pain rats were randomly assigned to the experimental groups ( $n=6$ in each group) and the behavior observations were performed in a blind manner to the experimental conditions. Rats were placed in the metal grid covered with a plastic box and allowed to be habituated to the testing environment for at least 30 min before conducting the behavioral assessment. The withdrawal threshold evoked by stimulation of the hindpaw was determined using a 2290 CE electrical von Frey hair (IITC Life Science, Woodland Hills, CA, USA) while the rat stood on a metal grid. The monofilament, which generated a force that ranged from 0.1 to $90 \mathrm{~g}$, was applied in the foot pad with increasing force until the rat suddenly withdraws its hindlimb. The lowest force evoking a withdrawal response was considered the threshold, which was averaged from triplicate measurement in an interval of approximately $1 \mathrm{~min}$.

\section{Primary cell cultures}

The spinal cord, extracted from the 1-day-old neonatal rats, was minced and digested in $0.05 \%$ trypsin for 10 $\mathrm{min}$. The dispersive cells after centrifugation were thereafter suspended in Dulbecco's modified Eagle's medium (DMEM) supplemented with $10 \%(\mathrm{v} / \mathrm{v})$ fetal bovine serum (FBS), penicillin $(100 \mathrm{U} / \mathrm{mL})$, and streptomycin $(100 \mu \mathrm{g} / \mathrm{mL})$. The cells were then plated to poly-L-lysine $(100 \mu \mathrm{g} / \mathrm{mL})$-coated flask and incubated at $37^{\circ} \mathrm{C}$ with $5 \%$ $\mathrm{CO}_{2}$ in the incubator. To obtain neuronal cells, the medium after $1.5 \mathrm{~h}$ of incubation was changed to neurobasal containing B27 supplement and $0.5 \mathrm{mM}$ glutamine for further culture. The purity of neuronal cells, determined by the neuronal nuclear antigen $(\mathrm{NeuN}) \mathrm{immu}$ noreactivity [21], was more than $85 \%$. All experiments were initiated 5-6 days after plating.

For glial cell cultures, cells were seeded into $75-\mathrm{cm}^{2}$ tissue culture flasks pre-coated with poly-L-lysine $\left(1 \times 10^{7}\right.$ cells/flask), and cultured at $37^{\circ} \mathrm{C}$. After 8 days of culture, 
microglial cells were obtained as a floating cell suspension after shaking the flask at $260 \mathrm{rpm}$ for $2 \mathrm{~h}$. Aliquots were transferred to plates and unattached cells were removed by washing with serum-free DMEM. Harvested microglial cells exhibited a purity $>95 \%$, as determined by the CD11b (OX42) immunoreactivity [77, 78]. All experiments were initiated $12-24 \mathrm{~h}$ after plating. To obtain astrocytes, the flask after 11 days of culture was shaken for $2 \mathrm{~h}$ and then the aliquots were removed. The cells were washed using PBS and incubated with $10 \mathrm{~mL}$ of $0.05 \%$ trypsin-ethylenediamine tetraacetic acid (Invitrogen, Grand Island, NY, USA) for $15 \mathrm{~min}$ to separate the oligodendrocytes. The trypsin was neutralized using $10 \mathrm{~mL}$ complete DMEM and the floating cell suspensions were discarded. A nearly intact layer of astrocytes in the bottom of the flasks were then trypsinized and subcultured conventionally. Prepared astrocytes showed a purity $90 \%$ as determined by the GFAP immunoreactivity [77, 78]. All experiments were initiated $12-24 \mathrm{~h}$ after plating.

\section{RNA isolation and quantitative real-time PCR (qRT-PCR)}

The spinal lumbar enlargements (L3-L5) were isolated from the bone cancer rats $1 \mathrm{~h}$ after the testing drug administration. The spinal homogenates and primary culture cells were mechanically homogenized in Trizol (Invitrogen) and the obtained total RNAs were reversely transcribed into cDNA using the ReverTraAce qPCR RT-kit (Toyobo, Osaka, Japan) according to the manufacturer's instruction. qRT-PCR amplification was performed in the Mastercycler ep realplex (Eppendorf, Hamburg, Germany) using the RealmasterMix (SYBR Green I) (Toyobo) in combination with the following primer sets: 5'CCAAGGTCATCCATGACGAC-3' and 5'TCCACAGTTCTGAGTGGC-3' for GAPDH, 5'-CCTAT CGGGTGGAGCACTTC-3' and 5'-TGGCTCTTCTCGG AGGTCAT-3' for the $\beta$-endorphin precursor proopiomelanocortin (POMC) [21], 5'-GGCTCAGCACTGCTATGT TGCC-3' and 5'-AGCATGTGGGTCTGGCTGACTG-3' for IL-10 (NM_012854.2), 5'-ACTGCCTGTCCTTGTGTT CC-3' and 5'-CCAAAGCAACCTCATTCTCC-3' for the dynorphin precursor prodynorphin (PDYN) [45]. For the relative quantification, the target gene expression was determined by the $\left(2^{-\Delta \Delta C t}\right)$ method after normalization to the gene of GAPDH CT values.

\section{$\beta$-Endorphin and IL-10 measurements}

The spinal cord, extracted from the bone cancer rats $1 \mathrm{~h}$ after the testing drug injection, was homogenized at $4000 \mathrm{rpm}$ for $15 \mathrm{~s}$ with a homogenizer (Fluko Equipment) in $10 \mathrm{mM}$ Tris- $\mathrm{HCl}(1 \mathrm{~g}$ of tissue $/ 5 \mathrm{~mL})$ and centrifuged at $4000 \mathrm{rpm}$ in $4{ }^{\circ} \mathrm{C}$ for $15 \mathrm{~min}$. For primary cells, cell culture supernatants were collected after treating with testing drugs for $2 \mathrm{~h}$ and then centrifuged at $5000 \mathrm{rpm}$ at $4{ }^{\circ} \mathrm{C}$ for $5 \mathrm{~min}$. The supernatants after centrifuge were prepared as the protein samples for ELISA. The protein concentrations in the spinal homogenates or cultured cell aliquots were measured by using the standard bicinchoninic acid protein assay (Beyotime Institute of Biotechnology, Jiangsu, China). The levels of IL-10 (eBioscience, Waltham, MA, USA) and $\beta$-endorphin (Phoenix Pharmaceuticals, CA, USA) were measured by using the enzyme-lined fluorescent immunoassay kits according to the manufacturer's instruction. A fluorescence microplate reader (Thermo Labsystem) was used to measure the relative fluorescence values and the concentration of IL-10 or $\beta$-endorphin was calculated by a calibration curve performed at the same time. The assays were validated with the linear range of $1-10,000 \mathrm{pg} / \mathrm{mL}$ for IL- 10 and $1-1000$ $\mathrm{pg} / \mathrm{mL}$ for $\beta$-endorphin. The $\beta$-endorphin ELISA kit had cross-reactivity with $\alpha$-endorphin $(100 \%)$ and $\gamma$-endorphin $(60 \%)$, but not with met-enkephalin $(0 \%)$ or leu-enkephalin $(0 \%)$, based on the manufacturer's information.

\section{Data calculation and statistical analysis}

The withdrawal threshold data was converted to the percentage of the maximum possible effect (\% MPE) by using the formula: (post-drug threshold in ipsilateral hindpaw pre-drug threshold in ipsilateral hindpaw)/(post-drug threshold in contralateral hindpaw - pre-drug threshold in ipsilateral hindpaw) $\times 100 \%$. The \% MPE values approximated to 100 indicate normal mechanical thresholds (i.e., near contralateral thresholds), while values approximated to 0 indicate mechanical allodynia. For the analysis of the dose-response curve, the following parameters were calculated by fitting non-linear least-squares curves to the relation $Y=a+b x$, where $x=[D]^{n} /\left(\mathrm{ED}_{50}{ }^{n}+[D]^{n}\right)$, i.e., the minimum effect, maximum effect $\left(E_{\max }\right)$, half-effective concentration $\left(E_{50}\right)$ and Hill coefficient $(n)$. The values of $\mathrm{ED}_{50}$ and $b\left(E_{\max }\right)$ were projected by yielding a minimum residual sum of squares of deviations from the theoretical curve [73].

The results are expressed as the mean \pm standard error of mean (SEM). Unpaired and two-tailed Student $t$ test, and one-way and repeated-measures two-way ANOVA were used to generate the statistical significance values. The post hoc Student-Newman-Keuls test was performed when the effect of the drug [dose] (for one-way ANOVA, the factor was drug [dose]; for two-way ANOVA, the factors were drug [dose], time and their interaction) was statistically significant. Probability values were two-tailed and the statistical significance criterion $p$ value was 0.05 . The statistical analysis and dose-response projection were performed by using Prism (version 7.01; GraphPad Software, Inc., San Diego, CA, USA).

\section{Results}

Cinobufagin produced mechanical antiallodynia and stimulated spinal expression of IL-10 and $\beta$-endorphin Mechanical allodynia started approximate 2 weeks after cancer cell tibia inoculation in rats and reached peak 
around 3 weeks after inoculation and remained consistent thereafter up to 4 weeks in our observation. The mechanical antiallodynic effects of cinobufagin were first assessed in the rat model of bone cancer pain by using von Frey filaments. A total of 36 female bone cancer pain rats were divided into six groups and received intrathecal injection of the vehicle (10\% DMSO and 20\% PEG400 in saline, $10 \mu \mathrm{L})$ and cinobufagin $(1,3,10,30$, and $100 \mu \mathrm{g})$, respectively. The paw withdrawal responses to mechanical stimulation were observed before and $0.5,1,2$, and $4 \mathrm{~h}$ after drug administration in both the contralateral and ipsilateral hindpaws. As shown in Fig. 1a, intrathecal injection of cinobufagin up to $100 \mu \mathrm{g}$ did not significantly alter withdrawal thresholds in the contralateral hindpaws during $4 \mathrm{~h}$ of observation. However, it alleviated mechanical allodynia in the ipsilateral hindpaws in a time-dependent manner, with the peak effect occurring between 30 and $60 \mathrm{~min}$ and the action duration longer than $3 \mathrm{~h}(p<$ 0.0001 , by repeated-measured two-way ANOVA followed by the post hoc Student-Newman-Keuls test). Cinobufagin-induced mechanical antiallodynia was also dose-dependent, with the $E_{\max }$ value of $90 \% \mathrm{MPE}$ and $\mathrm{ED}_{50}$ value of $6.4 \mu \mathrm{g}$ (95\% confidence limits of 2.6 to $15.4 \mu \mathrm{g})$ as projected from the withdrawal thresholds in the ipsilateral hindpaws $1 \mathrm{~h}$ after injection (Fig. 1b). There was no obvious sedation or impaired locomotor activity observed during the study. However, intrathecal injection of more than $250 \mu \mathrm{g}$ of cinobufagin caused abnormal behaviors including restless movements and tonic convulsion. In addition, the mechanical antiallodynic effects of cinobufagin were also evaluated in male bone cancer rats. As shown in Fig. 1c, intrathecal injection of cinobufagin $(30 \mu \mathrm{g})$ significantly alleviated mechanical allodynia in the ipsilateral hindpaws of male rats $(p<0.0001$, by repeatedmeasured two-way ANOVA followed by the post hoc Student-Newman-Keuls test) by a similar level to that of female rats, although it did not significantly alter withdrawal thresholds in the contralateral hindpaws.

Two groups of female bone cancer rats received intrathecal injection of the vehicle $(10 \mu \mathrm{L})$ and cinobufagin $(30 \mu \mathrm{g})$. The spinal lumbar enlargements were removed $1 \mathrm{~h}$ after intrathecal administration of cinobufagin. Intrathecal
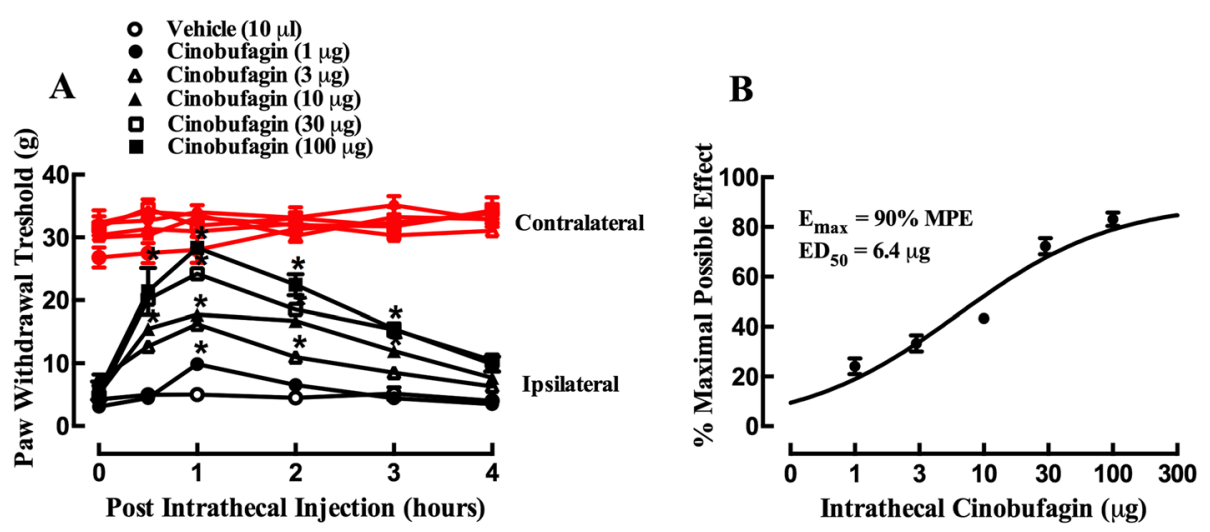

C

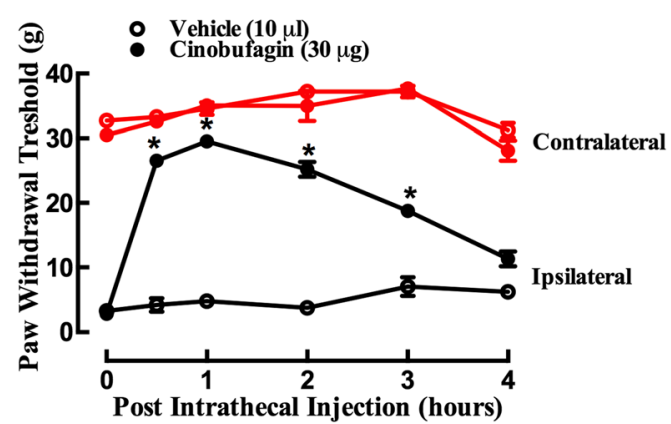

Fig. 1 Inhibitory effects of cinobufagin, given intrathecally, on mechanical allodynia in the rat model of bone cancer pain. The rats were inoculated with cancer cells for approximately 3 weeks and their mechanical thresholds were then measured by using electric von Frey filaments in both the contralateral and ipsilateral hindpaws. a Female bone cancer pain rats received single intrathecal administration of saline or cinobufagin $(1,3,10,30$, or $100 \mu \mathrm{g})$. $\mathbf{b}$ Dose-response analysis of cinobufagin on mechanical allodynia in the ipsilateral hindpaws of female bone cancer pain rats $1 \mathrm{~h}$ after its injection, best projected by the non-linear least-squares method. c Male bone cancer pain rats received single intrathecal administration of saline or cinobufagin $(30 \mu \mathrm{g})$. The data are presented as means \pm SEM ( $n=6$ per group). The asterisk denotes statistical significance $(p<0.0001)$ compared to the saline control group, by repeated-measured two-way ANOVA followed by the post hoc Student-Newman-Keuls test 
cinobufagin injection significantly upregulated the mRNA expression of IL-10 (Fig. 2a) and POMC (Fig. 2b), measured by using qRT-PCR, in the ipsilateral spinal cords $(p<0.01$, by unpaired and two-tailed Student $t$ test). In contrast, intrathecal cinobufagin did not significantly affect the PDYN mRNA expression (Fig. 2c).

Furthermore, the baseline IL-10 and $\beta$-endorphin levels were $43.1 \pm 7.8$ and $33.3 \pm 7.9 \mathrm{pg} / \mathrm{mL}$ in the spinal homogenates from the vehicle control rats, measured by using the commercial fluorescent immunoassay kits. Intrathecal cinobufagin $(30 \mu \mathrm{g})$ injection significantly increased the protein expression of IL-10 by 5.0 -fold and $\beta$-endorphin by 10.1 -fold, respectively ( $p<0.01$ by unpaired and two-tailed Student $t$ test; Fig. $2 \mathrm{~d}$, e).

\section{Cinobufagin specifically stimulated microglial expression of IL-10 and subsequent $\beta$-endorphin}

In order to test its stimulatory effect on the expression of IL-10 and $\beta$-endorphin in cultured primary cells, cinobufagin $(100 \mu \mathrm{M})$ was incubated for $2 \mathrm{~h}$ with microglia, neurons and astrocytes, originated from the spinal cords of neonatal rats. The gene expression of IL-10, POMC and prodynorphin from each set of cells was measured using qRT-PCR. As shown in Fig. 3a and b, treatment with cinobufagin for $2 \mathrm{~h}$ significantly stimulated the mRNA expression of IL-10 and POMC in cultured primary microglia $(p<0.001$, by unpaired and two- tailed Student $t$ test), but not in neurons or astrocytes. Further analysis showed that cinobufagin concentrationdependently increased the POMC expression in microglia with an $\mathrm{EC}_{50}$ value of $12.4 \mu \mathrm{M}$ (Fig. 3c). In contrast, treatment with cinobufagin at $100 \mu \mathrm{M}$ did not significantly alter the gene expression of PDYN in either cultured microglia, neurons, or astrocytes (Fig. 3d).

Moreover, the baseline IL-10 and $\beta$-endorphin levels in cultured microglia cells were $6.8 \pm 0.9$ and $49.2 \pm 18.2$ $\mathrm{pg} / \mathrm{mL}$. Exposure of cinobufagin $(100 \mu \mathrm{M})$ significantly increased the protein expression of IL-10 by 13.6 -fold and $\beta$-endorphin by 6.6 -fold, respectively $(p<0.01$ by unpaired and two-tailed Student $t$ test; Fig. 3e, f).

To further confirm the stimulatory effect of cinobufagin on the microglial expression of IL-10 and POMC, the microglial inhibitor minocycline [55, 65] was used. Cultured microglial cells were treated with minocycline $(60 \mu \mathrm{M}) 1 \mathrm{~h}$ followed by cinobufagin $(100 \mu \mathrm{M})$ and the gene expression of IL-10 and POMC was measured $2 \mathrm{~h}$ after treatment using qRT-PCR. Treatment with minocycline did not significantly alter the baseline expression of IL-10 or POMC, but its pretreatment significantly blocked cinobufagin-induced overexpression of IL-10 and POMC $(p<0.001$, by one-way ANOVA followed by the post hoc Student-Newman-Keuls test; Fig. 3g, h).

In order to reveal whether IL-10 induced $\beta$-endorphin expression or vice versa following cinobufagin treatment,

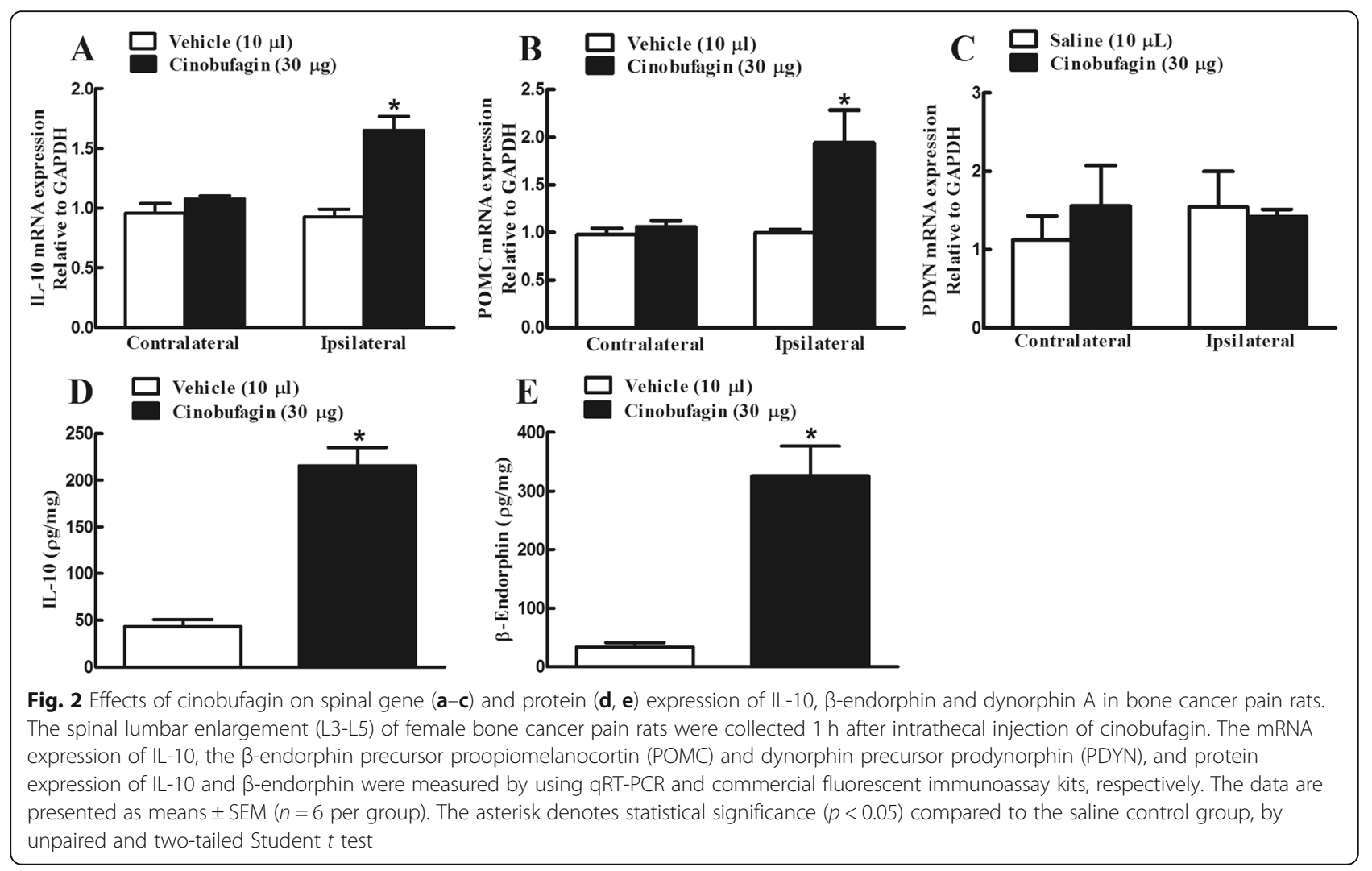




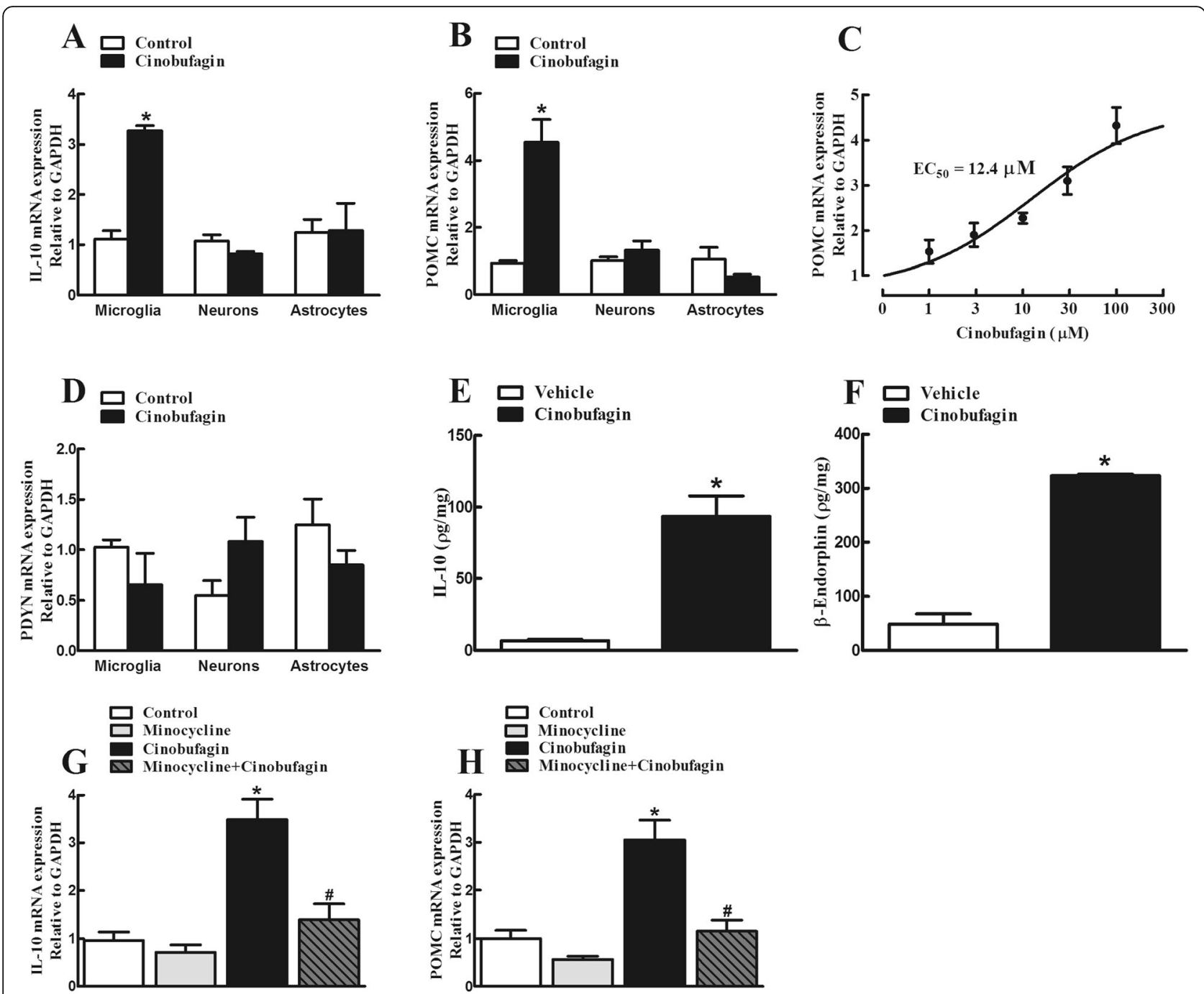

Fig. 3 Effects of cinobufagin on the gene (a-d) and protein (e, $\mathbf{f}$ ) expression of IL-10, the $\beta$-endorphin precursor proopiomelanocortin (POMC) and dynorphin precursor prodynorphin (PDYN) in the primary cultures of spinal microglia, neurons, and astrocytes. $\mathbf{g}, \mathbf{h}$ The blockade effect of the microglial inhibitor minocycline on cinobufagin-induced gene overexpression of IL-10 and POMC. The primary culture cells, originated from the spinal cords of 1-day-old neonatal rats, were collected $2 \mathrm{~h}$ after cinobufagin incubation. For the blockade study, minocycline was incubated 1 h prior to cinobufagin treatment. The mRNA expression of IL-10, POMC, and PDYN was measured by using qRT-PCR. The data are presented as means \pm SEM ( $n=3$ independent repeats with duplicates). The asterisk and number sign denote statistical significance $(p<0.001)$ compared to the control group and cinobufagin group, respectively, by unpaired and two-tailed Student $t$ test (a-f) or one-way ANOVA followed by the post hoc Student-Newman-Keuls test (g, h)

the effects of the IL-10 and $\beta$-endorphin neutralizing antibodies were assessed on the gene expression of IL-10 and POMC. Cultured microglial cells were treated with the IL10 antibody $(4 \mu \mathrm{g} / \mathrm{mL})$ or $\beta$-endorphin antiserum $(1: 300$ dilution) $2 \mathrm{~h}$ followed by cinobufagin $(100 \mu \mathrm{M})$ and the gene expression of IL-10 and POMC was measured $2 \mathrm{~h}$ later. As shown in Fig. 4a and b, treatment with cinobufagin significantly stimulated the gene expression of IL-10 and POMC, compared to the control group. Pretreatment with the IL-10 antibody for $2 \mathrm{~h}$ did not significantly alter baseline expression of IL-10 or POMC, but blocked cinobufagin-stimulated overexpression of POMC but not
IL-10 ( $p<0.0001$, by one-way ANOVA followed by the post hoc Student-Newman-Keuls test). In contrast, treatment with the $\beta$-endorphin antiserum did not alter either the baseline or cinobufagin-stimulated gene expression of IL-10 or POMC (Fig. 4c, d).

\section{Cinobufagin exhibited mechanical antiallodynia through spinal microglial expression of IL-10 and $\beta$-endorphin} To assess whether cinobufagin exhibited antinociception through the spinal microglial IL- $10 / \beta$-endorphin axis, the microglial inhibitor minocycline was first employed. The female bone cancer pain rats were divided into two 
groups and received intrathecal injection of normal saline $(10 \mu \mathrm{L})$ or minocycline $(100 \mu \mathrm{g})$ followed by cinobufagin $(30 \mu \mathrm{g}) \quad 4 \mathrm{~h}$ later. Intrathecal injection of cinobufagin produced time-dependent mechanical antiallodynia in the ipsilateral hindpaws. Pretreatment with intrathecal injection of minocycline did not significantly affect baseline withdrawal thresholds in the ipsilateral hindpaws, but completely blocked cinobufagin-induced mechanical antiallodynia $(p<0.0001$, by repeatedmeasures two-way ANOVA followed by the post hoc Student-Newman-Keuls test; Fig. 5a).

In addition, two groups of female bone cancer pain rats received intrathecal injection of $10 \mu \mathrm{L}$ of normal saline or $2 \mu \mathrm{g}$ of the IL-10 antibody followed by $30 \mu \mathrm{g}$ of cinobufagin $30 \mathrm{~min}$ later. Intrathecal injection of cinobufagin in the ipsilateral hindpaws produced a timedependent mechanical antiallodynia, which was significantly attenuated by the pretreatment with intrathecal injection of the IL-10 antibody ( $p<0.0001$, by repeatedmeasures two-way ANOVA followed by the post hoc Student-Newman-Keuls test) although it did not significantly alter the baseline withdrawal thresholds (Fig. 5b).
Furthermore, two groups of female bone cancer pain rats received intrathecal injection of normal saline $(10 \mu \mathrm{L})$ or the $\beta$-endorphin antiserum (1:10 dilution, $10 \mu \mathrm{L})$ followed by cinobufagin $(30 \mu \mathrm{g}) 30 \mathrm{~min}$ later. The pretreatment with intrathecal injection of the $\beta$-endorphin antiserum did not have a significant effect on the baseline withdrawal thresholds, but effectively attenuated cinobufagin-induced mechanical antiallodynia $(p<0.0001$, by repeated-measures twoway ANOVA followed by the post hoc Student-NewmanKeuls test; Fig. 5c).

As $\beta$-endorphin is an endogenous ligand of $\mu$-opioid receptors [32, 44], its involvement in cinobufagin-induced mechanical antiallodynia was investigated. Two groups of female bone cancer pain rats received intrathecal injection of normal saline $(10 \mu \mathrm{L})$ or the selective $\mu$-opioid receptor antagonist CTAP $(10 \mu \mathrm{g})$ followed by cinobufagin $(30 \mu \mathrm{g})$ 30 min later. As shown in Fig. 5d, the pretreatment with intrathecal injection of CTAP effectively blocked the antinociceptive effect of cinobufagin in the ipsilateral hindpaws $(p<0.0001$, by repeated-measures two-way ANOVA followed by the post hoc Student-Newman-Keuls test), although it did not significantly affect the baseline withdrawal thresholds.
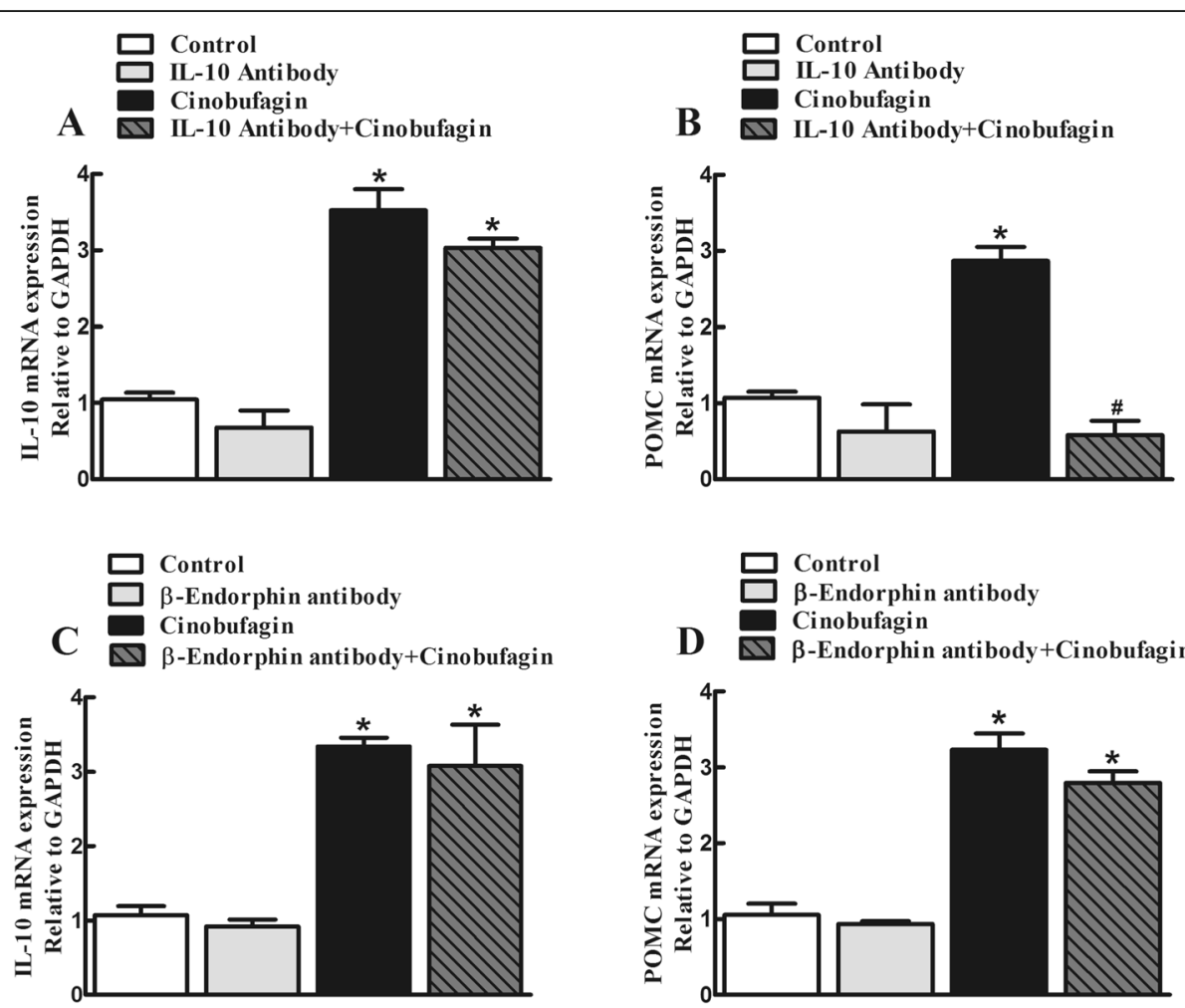

Fig. 4 Effects of the IL-10 antibody $(\mathbf{a}, \mathbf{b})$ and $\beta$-endorphin antiserum $(\mathbf{c}, \mathbf{d})$ on cinobufagin-stimulated gene expression of IL-10 and $\beta$-endorphin precursor proopiomelanocortin (POMC) in primary cultures of spinal microglia. Microglia cells, originated from the spinal cords of 1-day-old neonatal rats, were first treated with the IL-10 antibody or $\beta$-endorphin antiserum for $2 \mathrm{~h}$ followed by cinobufagin, and were collected $2 \mathrm{~h}$ after the cinobufagin treatment. The mRNA expression of IL-10 and POMC was measured using qRT-PCR. The data are presented as means \pm SEM $(n=$ 3 independent repeats with duplicates). The asterisk denotes statistical significance $(p<0.001)$ compared to the control group, by unpaired and two-tailed Student $t$ test 

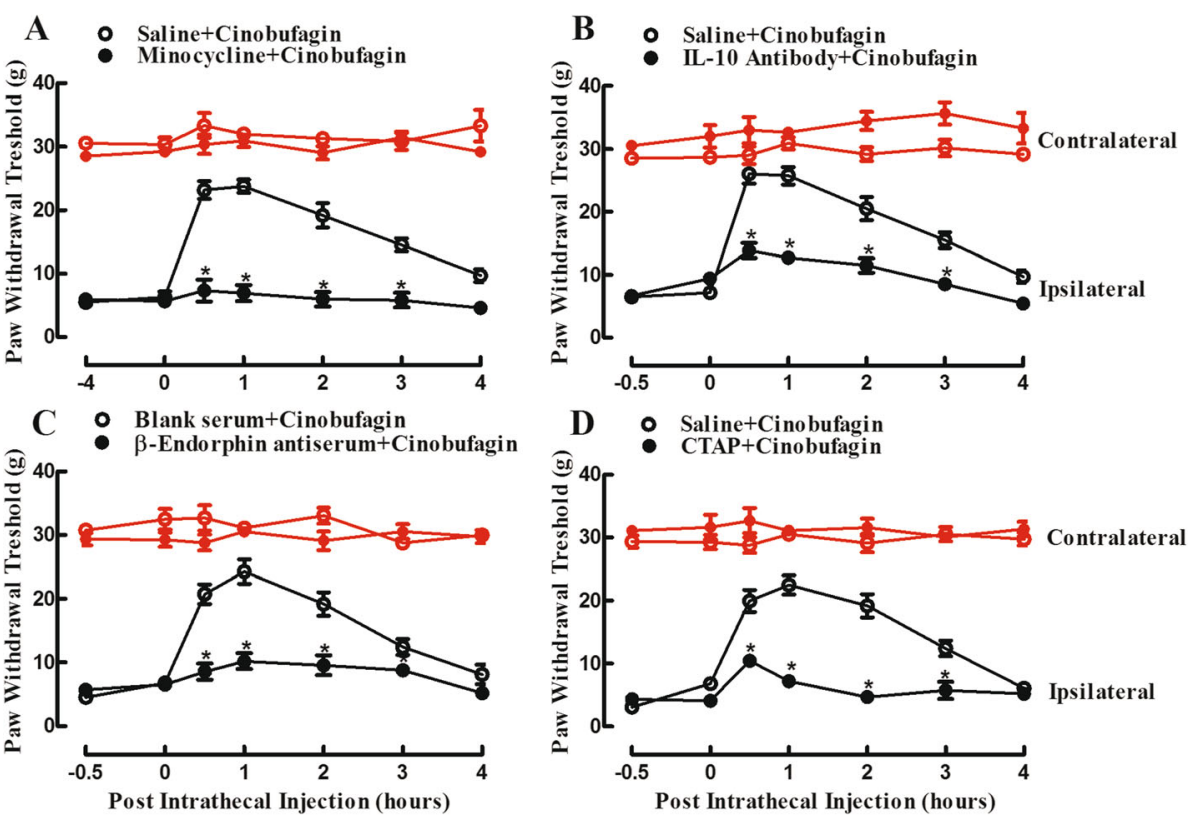

Fig. 5 Blockade effects of intrathecal injection of the microglial inhibitor minocycline (a), IL-10 antibody (b), $\beta$-endorphin antiserum (c), and selective $\mu$-opioid receptor CTAP (d) on spinal cinobufagin-induced mechanical antiallodynia in the rat model of bone cancer pain. Female bone cancer pain rats, approximately 3 weeks after cancer cell inoculation, received two intrathecal injections, and mechanical thresholds in both the contralateral and ipsilateral hindpaws were measured by using electric von Frey filaments. Minocycline was intrathecally injected $4 \mathrm{~h}$ prior to cinobufagin treatment, whereas the IL-10 antibody, $\beta$-endorphin antiserum, and CTAP were intrathecally given 30 min before cinobufagin injection. Withdrawal thresholds were measured in both the contralateral and ipsilateral hindpaws. The data are presented as means \pm SEM $(n=6$ per group). The asterisk denotes statistical significance $(p<0.05)$ compared to the vehicle control group, by repeated-measured two-way ANOVA followed by the post hoc Student-Newman-Keuls test

\section{Activation of the a7-nAChR mediated cinobufagin- induced spinal microglial expression of IL-10/ $\beta$-endorphin and mechanical antiallodynia}

To test whether activation of the $\alpha 7-n A C h R$ was responsible for cinobufagin-stimulated microglial expression of IL-10 and $\beta$-endorphin, the specific $\alpha 7-n A C h R$ antagonist methyllycaconitine [6] was employed. Cultured primary microglial cells, originated from the spinal cords of neonatal rats, were treated with methyllycaconitine $(10 \mathrm{nM})$ [76] $30 \mathrm{~min}$ later followed by cinobufagin $(100 \mu \mathrm{M})$, and the gene expression of IL10 and POMC was measured $2 \mathrm{~h}$ after the treatment using qRT-PCR. Methyllycaconitine treatment did not significantly alter the baseline IL-10 or POMC expression in microglia, but its pretreatment entirely blocked cinobufagin-induced overexpression of IL-10 and POMC $(p<0.001$, by one-way ANOVA followed by the post hoc Student-Newman-Keuls test; Fig. 6a, b).

To further confirm the stimulatory effects of $\alpha 7-n A C h R$ activation on the IL-10 and $\beta$-endorphin expression, the specific $\alpha 7-n A C h R$ agonist PHA-543613 [89] was also used in the study. Cultured spinal primary microglial cells were treated with methyllycaconitine $(10 \mathrm{nM}) 30 \mathrm{~min}$ later followed by PHA-543613 $(100 \mu \mathrm{M})$, and the gene expression of IL-10 and POMC was measured $2 \mathrm{~h}$ later using
qRT-PCR. As shown in Fig. 6c and d, treatment with PHA543613 increased the gene expression of IL-10 and POMC, which was blocked by the pretreatment with methyllycaconitine $(p<0.05$, by one-way ANOVA followed by the post hoc Student-Newman-Keuls test). In addition, treatment with PHA-543613 $(100 \mu \mathrm{M})$ for $2 \mathrm{~h}$ significantly increased the protein expression of IL-10 and $\beta$-endorphin in primary cultures of microglia $(p<0.0001$, by unpaired and twotailed Student $t$ test; Fig. 6e and f). To investigate whether the stimulatory effect of cinobufagin on the IL-10 and $\beta$ endorphin expression was possibly via the inhibition of $\mathrm{Na}^{+}-\mathrm{K}^{+}$ATPase, the $\mathrm{Na}^{+}-\mathrm{K}^{+}$ATPase inhibitor ouabain [37] was tested. As shown in Fig. $6 \mathrm{~g}$ and $\mathrm{h}$, treatment with ouabain $(10 \mu \mathrm{M})$ failed to affect the protein expression of IL-10 or $\beta$-endorphin in primary cultures of microglia.

Activation of mitogen-activated protein kinases (MAPKs), including p38, extracellular signal-related kinases $1 / 2$ (ERK1/2) and c-Jun N-terminal kinases (JNK) [75], was involved in $\alpha 7-n A C h R$-induced inhibition of neuroinflammation $[23,49,85]$. To illustrate which subtype(s) of MAPKs were involved in cinobufagin-induced IL-10/ $\beta$-endorphin expression, the specific p38 inhibitor SB203580, JNK inhibitor SP600125, and ERK1/2 inhibitor UO126 were used. Cultured microglial cells were treated with SB203580 $(30 \mu \mathrm{M})$, SP600125 $(50 \mu \mathrm{M})$, or UO126 $(50 \mu \mathrm{M}) 30 \mathrm{~min}$ 

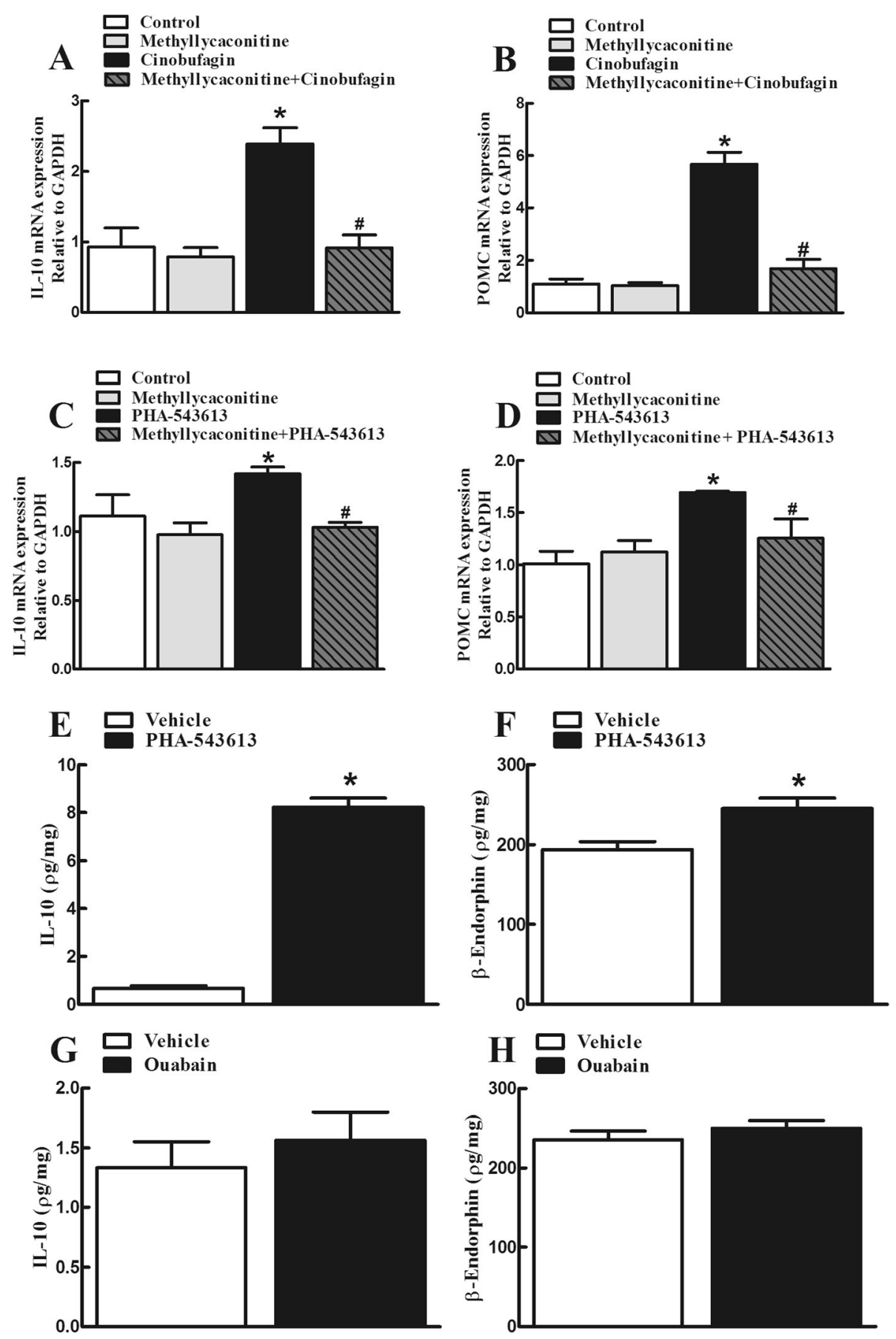

Fig. 6 Blockade effects of the specific a7-nicotinic acetylcholine receptor (a7-nAChR) antagonist methyllycaconitine on cinobufagin (a, b)- and the specific a7-nAChR agonist PHA-543613 (c, d)-stimulated gene expression of IL-10 and the $\beta$-endorphin precursor proopiomelanocortin (POMC) in primary cultures of spinal microglia. e-h. Effects of PHA-543613 and ouabain on the protein expression of IL-10 and $\beta$-endorphin. Microglial cells, originated from the spinal cords of 1-day-old neonatal rats, were incubated with cinobufagin (100 $\mu \mathrm{M})$, PHA-543613 (100 $\mu \mathrm{M})$, or ouabain $(10 \mu \mathrm{M})$. The mRNA and protein expression of IL-10 and POMC was measured $2 \mathrm{~h}$ later using qRT-PCR and the commercial kits, respectively. For the methyllycaconitine blockade study, methyllycaconitine was incubated $0.5 \mathrm{~h}$ prior to cinobufagin or PHA-543613 treatment. The data are presented as means \pm SEM ( $n=3$ independent repeats with duplicates). The asterisk and number sign denote statistical significance $(p<0.001)$ compared to the control and cinobufagin group, respectively, by one-way ANOVA followed by the post hoc Student-Newman-Keuls test 
followed by cinobufagin $(100 \mu \mathrm{M})$, and the gene expression of IL-10 and POMC was measured $2 \mathrm{~h}$ after cinobufagin treatment using qRT-PCR. As shown, treatment with SB203580 (Fig. 7a, b), SP600125 (Fig. 7c, d), or UO126 (Fig. $7 \mathrm{e}, \mathrm{f}$ ) did not significantly alter baseline gene expression of IL-10 or POMC. However, each treatment significantly inhibited cinobufagin-induced overexpression of IL-10 and POMC $(p<0.0001$, by one-way ANOVA followed by the post hoc Student-Newman-Keuls test).

Futhermore, the inhibitory effect of methyllycaconitine on cinobufagin-induced mechanical antiallodynia was assessed. Two groups of female bone cancer pain rats received intrathecal injection of normal saline $(10 \mu \mathrm{L})$ or methyllycaconitine $(10 \mu \mathrm{g})$ followed by cinobufagin $(30 \mu \mathrm{g})$ 30 min later, and withdrawal thresholds were measured in both the contralateral and ipsilateral hindpaws prior to or post the last injection. As shown in Fig. 8a, intrathecal injection of methyllycaconitine did not significantly alter baseline withdrawal thresholds in either contralateral or ipsilateral hindpaws, whereas cinobufagin produced marked mechanical antiallodynia in the ipsilateral hindpaws. Pretreatment with methyllycaconitine blocked cinobufagin-induced mechanical antiallodynia $(p<0.0001$, by repeated-measures two-way ANOVA followed by the post hoc Student-Newman-Keuls test).

For comparison, the mechanical antiallodynic effects of PHA-543613 and ouabain were also assessed. Four groups of female bone cancer pain rats received intrathecal injection of normal saline $(10 \mu \mathrm{l})$ or methyllycaconitine $(10 \mu \mathrm{g})$ followed by an intrathecal injection of PHA-543613 $(12 \mu \mathrm{g})$ or ouabain $(2.5 \mu \mathrm{g}) 30 \mathrm{~min}$ later [90, 92]. Intrathecal injection of PHA-543613 significantly inhibited mechanical allodynia in the ipsilateral hindpaws, without affecting mechanical thresholds in the contralateral hindpaws. Pretreatment with intrathecal injection of methyllycaconitine blocked PHA543613 -induced mechanical antiallodynia $(p<0.0001$, by repeated-measures two-way ANOVA followed by the post hoc Student-Newman-Keuls test; Fig. 8b). In contrast, intrathecal injection of ouabain exerted a timedependent mechanical antiallodynia, which was not significantly altered by the pretreatment with intrathecal injection of methyllycaconitine (Fig. 8c). No obvious behavioral changes of ouabain were observed during the study. However, intrathecal injection of more than $5 \mu \mathrm{g}$ of ouabain produced abnormal behavior changes such as shortness of breath and tonic convulsion.

The CRF receptor was associated with microglial expression of $\beta$-endorphin $[8,33,40]$ and Bufonis venenum stimulated CRF expression $[9,10]$. Thus, the possible involvement of the CRF receptor in cinobufagin-induced mechanical antiallodynia was finally tested. Two groups of female bone cancer pain rats received intrathecal injection of normal saline $(10 \mu \mathrm{L})$ and the specific CRF receptor antagonist $\alpha$-helical CRF $(9-41)(20 \mu \mathrm{g})[32,59]$ respectively followed by cinobufagin $(30 \mu \mathrm{g}) 30 \mathrm{~min}$ later, and withdrawal thresholds were measured in both the contralateral and ipsilateral hindpaws prior to or post the last injection. In contrast to methyllycaconitine, pretreatment with intrathecal injection of $\alpha$-helical CRF (941) failed to block the antiallodynic effect of cinobufagin in the ipsilateral hindpaws (Fig. 8d).

\section{Discussion}

Cancer pain particularly bone cancer pain remains to be one of the most challenging symptoms to control [36, 51]. Current major drug treatment for advanced cancer pain is strong opioids, such as morphine, methadone, oxycodone, hydromorphone, and fentanyl [26]. However, the treatment success rate is still low especially with tremendous adverse effects, including oversedation, respiration inhibition, constipation, analgesic tolerance and hyperalgesia, and physical dependence and addiction. It is thus critical to discover and develop novel nonaddictive, highly effective and low-toxicity interventions for the treatment of cancer pain. Bufonis venenum has been prescribed in China for the treatment of cancers [2, 12]. Since it was serendipitously found to effectively relieve pain in bone metastasis patients during anticancer treatment [50], Bufonis venenum has been frequently used to treat a variety of cancer pains as it also has anticancer effects $[22,50]$. The clinical analgesic efficacy was supported by the findings that multiple daily intraperitoneal injections of Bufonis venenum produced mechanical antiallodynia and thermal antihyperalgesia in the mouse model of paw cancer pain $[9,10]$. Our current study demonstrated that intrathecal injection of cinobufagin, probably the most abundant bufadienolide in Bufonis venenum, inhibited mechanical allodynia in the ipsilateral hindpaws of female bone cancer rats in a dosedependent manner, with an $E_{\max }$ of $90 \% \mathrm{MPE}$ and $\mathrm{ED}_{50}$ of $6.4 \mu \mathrm{g}$. However, intrathecal cinobufagin at the doses tested up to $100 \mu \mathrm{g}$ did not affect normal mechanical thresholds in the contralateral hindpaws. Accumulated evidence indicates that gender is an important factor in pain modulation and the sex hormones difference influences the response to opioids for pain treatment [19, 57]. Thus, the mechanical antiallodynic effects of cinobufagin were also assessed in male cancer pain rats. Our result demonstrated that intrathecal injection of cinobufagin similarly inhibited mechanical allodynia in the ipsilateral hindpaws of male bone cancer rats. Therefore, all the results confirm that Bufonis venenum and its derived cinobufagin are effectively analgesic in bone cancer pain and provide a new molecular scaffold of cinobufagin for chemical modification and development as a painkiller for cancer pain. 

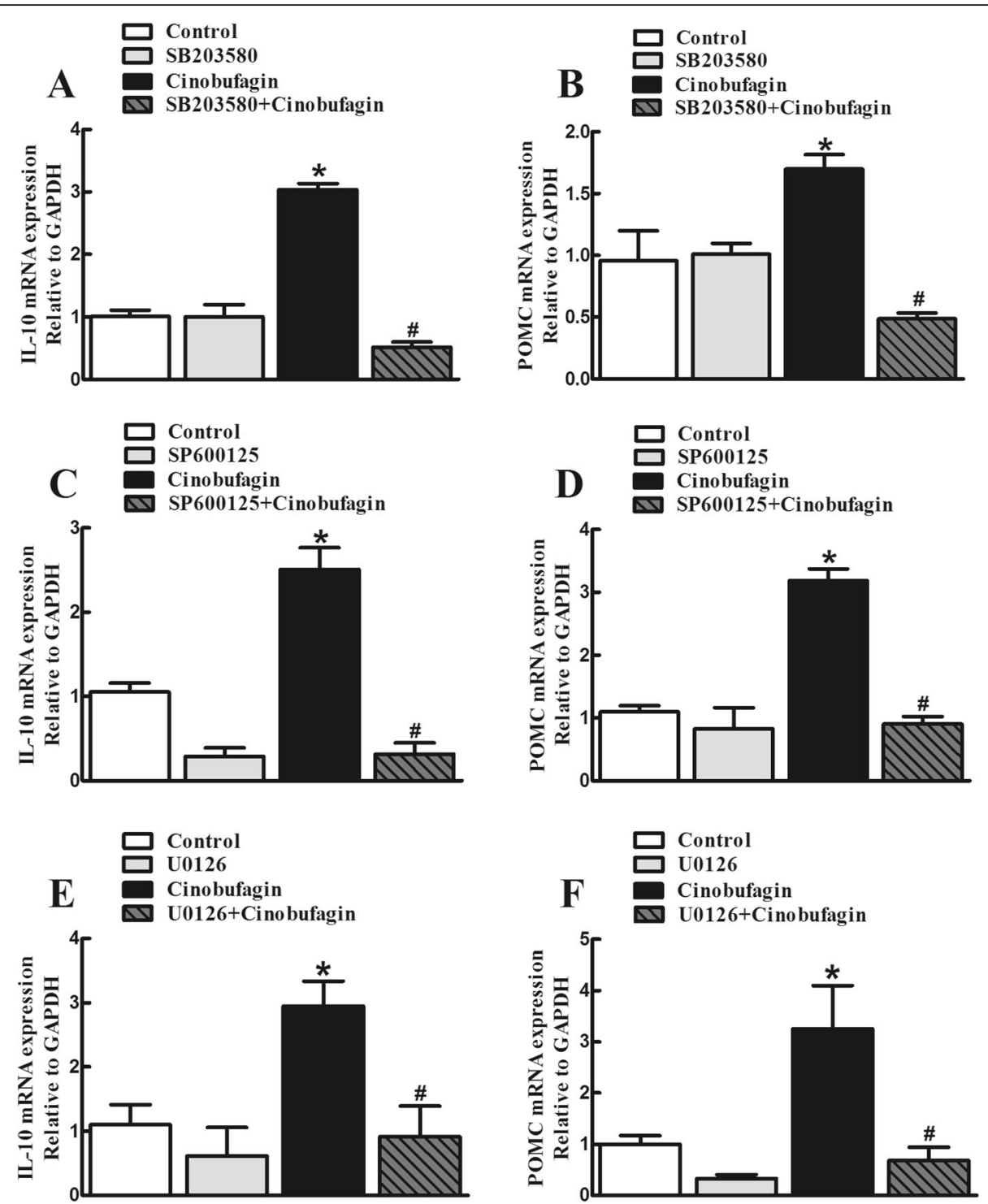

Fig. 7 Blockade effects of the specific p38 mitogen-activated protein kinase (MAPK) activation inhibitor SB203580 (a, b), JNK MAPK activation inhibitor SP600125 (c, d), and ERK1/2 MAPK activation inhibitor U0126 (e, f) on cinobufagin-stimulated gene overexpression of IL-10 and the $\beta$ endorphin precursor proopiomelanocortin (POMC) in primary cultures of spinal microglia. Cultured primary microglial cells, originated from the spinal cords of 1-day-old neonatal rats, incubated with each MAPK inhibitor for 1 hour followed by cinobufagin (100 $\mu \mathrm{M})$ for $2 \mathrm{~h}$. The mRNA expression of IL-10 and POMC was measured using qRT-PCR. The data are presented as means \pm SEM ( $n=3$ independent repeats with duplicates). The asterisk and number sign denote statistical significance $(p<0.001)$ compared to the control group and cinobufagin group, respectively, by one-way ANOVA followed by the post hoc Student-Newman-Keuls test

More strikingly, the present study reveals that cinobufagin induces mechanical antiallodynia through the spinal microglial IL-10/ $\beta$-endorphin pathway. This notion is supported by the following findings: (1) Treatment with cinobufagin in cultured primary spinal microglial cells, but not neurons or astrocytes, specifically stimulated the gene and protein expression of IL-10 and POMC but not PDYN, which was inhibited by the pretreatment with the microglial inhibitor minocycline. In addition, treatment with cinobufagin also stimulated other M2 biomarkers Arg1, CD206, and IL-4 in cultured microglia (unpublished data).
Moreover, pretreatment with the IL-10 antibody prevented cinobufagin-induced stimulatory effect on the gene expression of POMC but not IL-10; whereas pretreatment with the $\beta$-endorphin antiserum failed to affect its stimulatory effect on the mRNA expression of either IL-10 or POMC. The results indicated that cinobufagin-stimulated microglial expression of IL-10 and subsequent POMC and not vice versa. The conclusion is supported by the recent findings that IL-10 treatment directly stimulated microglial expression of $\beta$-endorphin, whereas $\beta$-endorphin treatment did not have a significant stimulatory effect on 

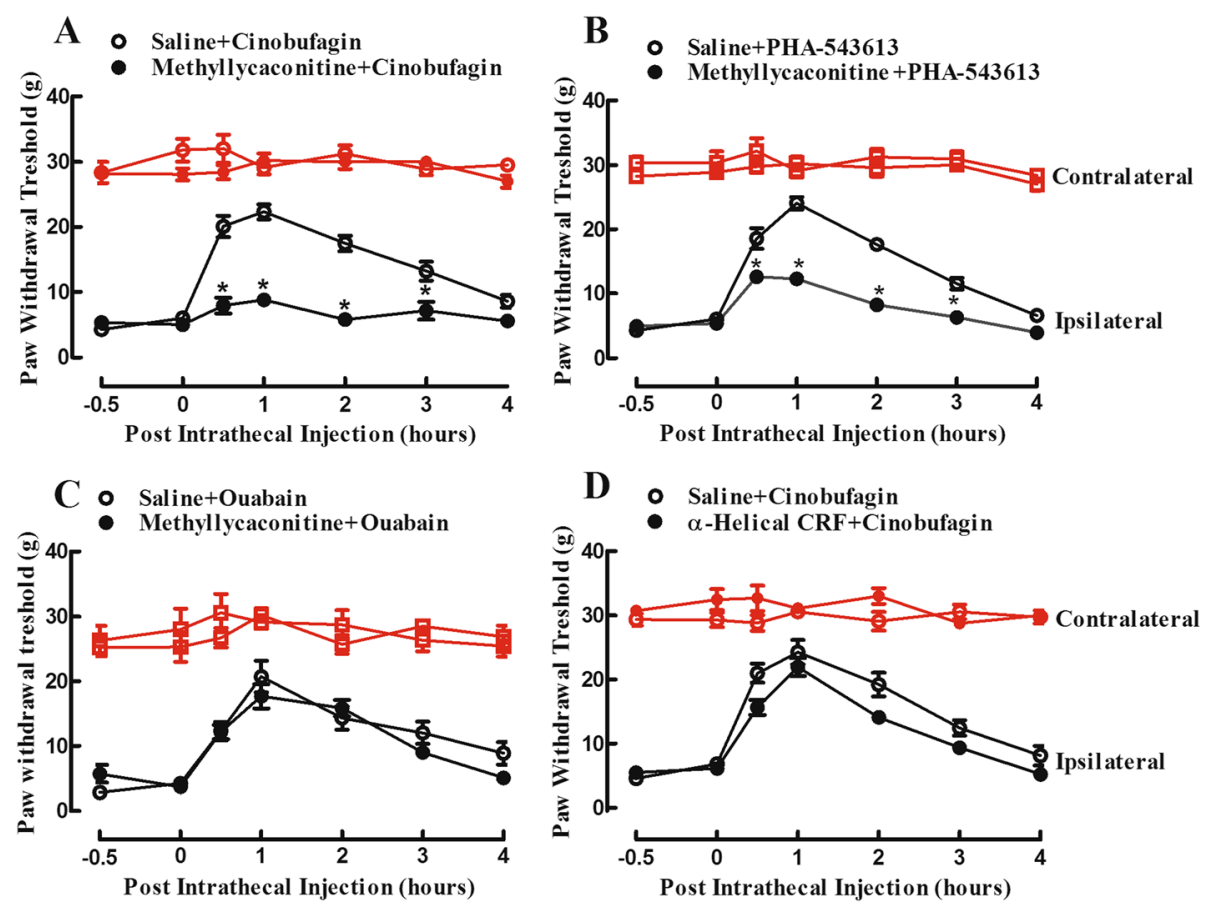

Fig. 8 Effects of the specific a7-nicotinic acetylcholine receptor (a7-nAChR) antagonist methyllycaconitine (a-c) and CRF receptor antagonist ahelical CRF (9-41) (d) on cinobufagin-, PHA-543613-, or ouabain-induced mechanical antiallodynia in the rat model of bone cancer pain. Female bone cancer pain rats, approximately 3 weeks after cancer cell inoculation, received intrathecal injection of the vehicle (10 $\mu \mathrm{L})$, methyllycaconitine $(10 \mu \mathrm{g})$ or a-helical CRF $(9-41)(20 \mu \mathrm{g}) 0.5 \mathrm{~h}$ later followed by cinobufagin $(30 \mu \mathrm{g})$, PHA-543613 $(12 \mu \mathrm{g})$, or ouabain $(2.5 \mu \mathrm{g})$, and mechanical thresholds in both the contralateral and ipsilateral hindpaws were measured by using electric von Frey filaments. The data are presented as means \pm SEM ( $n=6$ per group). The asterisk denotes statistical significance $(p<0.05)$ compared to the vehicle control group, by repeatedmeasured two-way ANOVA followed by the post hoc Student-Newman-Keuls test

IL-10 expression [71, 77-79]. Furthermore, pretreatment with the IL-10 antibody prevented the GLP-1 receptor agonist exenatide- and GPR40 agonist GW90851-induced expression of $\beta$-endorphin but not IL-10, whereas the $\beta$ endorphin antiserum did not have any effects on their expression of $\beta$-endorphin or IL-10 [52, 79]. (2) Intrathecal injection of cinobufagin significantly stimulated the gene and protein expression of IL-10 and $\beta$-endorphin but not dynorphin A in the ipsilateral spinal cords. The results were in agreement with the previous findings that multiple daily intraperitoneal injections of Bufonis venenum increased the $\beta$-endorphin level in plasma and $\beta$ endorphin immunostaining in the tumor xenograft tissues of paw cancer pain mice $[9,10]$. (3) Causally, the spinal cinobufagin-induced mechanical antiallodynia was nearly entirely attenuated by the pretreatment with intrathecal injection of the microglial inhibitor minocycline, IL-10 neutralizing antibody, $\beta$-endorphin antiserum, and specific $\mu$-opioid receptor antagonist CTAP. Our previous study also demonstrated that intrathecal IL-10 in neuropathic rats produced mechanical antiallodynia and thermal antihyperalgesia, which were prevented by the pretreatment with the $\beta$-endorphin antiserum and CTAP [55, 56, 77, 78].
Expressed in astrocytes and microglial cells in addition to neurons, $\alpha 7-n A C h R s$ are closely associated with antineuroinflammation through the cholinergic nervous system and may be a promising target molecule for the treatment Alzheimer's disease, schizophrenia, Parkinson disease, and chronic pain [1, 14, 27, 38, 62, 66, 83]. It was recently reported that gavage administration of cinobufagin produced antinociception in the mouse models of thermal and chemical pain, which was prevented by the intraperitoneal injection of the specific $\alpha 7-n A C h R$ antagonist methyllycaconitine and intrathecal injection of the gene silencer siRNA/ $\alpha 7-n A C h R$ [82]. The present study confirmed that intrathecal injection of methyllycaconitine in the rat model of bone cancer pain blocked spinal cinobufagin-induced mechanical antiallodynia and pretreatment with methyllycaconitine in cultured primary microglial cells attenuated cinobufagin-stimulated gene expression of IL-10 and POMC. Furthermore, treatment with the specific $\alpha 7-n A C h R$ agonist PHA-543613 in cultured primary microglia stimulated gene and protein expression of IL-10 and $\beta$-endorphin, and intrathecal PHA543613 in bone cancer pain rats produced mechanical antiallodynia, both of which were blocked by the 
pretreatment with methyllycaconitine. These results suggest that cinobufagin and PHA-543613 activate $\alpha 7-n A C h R s$ to stimulate spinal microglial expression of IL-10 and $\beta$-endorphin and produce mechanical antiallodynia in bone cancer pain. However, this study is limited by lacking elucidated interactions of cinobufagin with the $\alpha 7-\mathrm{nAChR}$ at the molecular level. Further studies are needed to determine the efficiency and mode of cinobufagin in the in vitro experiments (such as radioligand analysis, electrophysiology or calcium imaging FLIPR assay) with $\alpha 7$-nAChRs expressed in the Xenopus oocytes or appropriate cell lines. On the other hand, CRF receptors are also associated with microglial expression of $\beta$-endorphin $[8,33,40]$ and Bufonis venenum was reported to stimulate CRF expression [9, 10]. However, our study showed that the CRF receptor antagonist $\alpha$-helical CRF (9-41) was ineffective in blockade of cinobufagin-induced antiallodynia, implying that the spinal CRF system may not mediate cinobufagin-induced $\beta$-endorphin expression via IL-10 and subsequent mechanical antiallodynia.

Cinobufagin and its analogs inhibited $\mathrm{Na}^{+}-\mathrm{K}^{+}$ATPase $[11,17,18]$, which might also be the mechanisms accounting for their antinociception as inhibition of $\mathrm{Na}^{+}$$\mathrm{K}^{+}$ATPase leads to antinociception [15, 68]. Indeed, intrathecal treatment with ouabain in bone cancer pain produced marked mechanical antiallodynia which was not reversed by the $\alpha 7-n A C h R$ antagonist. However, microglia do not express functional $\mathrm{Na}^{+}-\mathrm{K}^{+}$ATPase, and $\mathrm{H}^{+} / \mathrm{K}^{+}$-ATPase instead appears to vicariate its role in microglia $[5,61]$. It was true that treatment with ouabain did not stimulate the expression of IL-10 and $\beta$-endorphin in primary microglial cells in our study. Thus, the stimulatory effect of cinobufagin on IL-10 and $\beta$-endorphin expression may not be due to its inhibition of $\mathrm{Na}^{+}-\mathrm{K}^{+}$ATPase $[4,16]$. Taken together, all these results suggest that cinobufagin produces mechanical antiallodynia by activating $\alpha 7-n A C h R s$, rather than inhibition of $\mathrm{Na}^{+}-\mathrm{K}^{+}$ATPase, and that microglial activation of $\alpha 7$-nAChRs triggers the IL-10/ $\beta$-endorphin antinociceptive pathway in painful hypersensitivity states. On the other hand, Bufanis venenum and bufadienolide have been reported to exhibit various sideeffects or toxicities in the central nervous and cardiovascular systems, such as shortness of breath, seizure, tachecardia, cardiac arrhythmia, and even coma [70, 81, 82];). Truly, the behavioral toxicities such as shortness of breath, restless movements, and tonic convulsion were observed after the intrathecal injection of more than $250 \mu \mathrm{g}$ of cinobufagin or more than $5 \mu \mathrm{g}$ of ouabain. The side-effects of cinobufagin are probably due to inhibition of $\mathrm{Na}^{+}-\mathrm{K}^{+}$ATPase expressed in neurons and cardiocytes ([11, 17, 18, 20, 70]. It is thus suggested that Bufanis venenum- and its effective ingredients-induced side-effects or toxicities are separated from their antinociception.

The notion that agonism of microglial $\alpha 7-n A C h R$ triggers IL-10/ $\beta$-endorphin pathway is further supported by the facts that the specific inhibitors of MAPK activation attenuated cinobufagin-stimulated IL-10/ $\beta$-endorphin expression in microglial cells. MAPKs are a family of evolutionally conserved molecules including p38, JNK, and ERK1/2 [75] and have been suggested to be involved in the antiinflammatory properties of $\alpha 7-n A C h R s$ possibly through modulation of inflammatory cytokine release [23, 49, 60, 69, 85]. Our study demonstrated that the specific JNK activation inhibitor SP600125, ERK1/2 activation inhibitor UO126 and p38 activation inhibitor SB203580 significantly blocked the gene expression of IL-10 and POMC in cultured microglia. The results agree with previous findings in which each subtype of MAPKs was involved in the production of IL-10 in human alveolar macrophages and monocytes $[7,28,29,39,58$, 63, 64, 93]. These results suggest that each ERK1/2, JNK, and p38 MAPK activation is associated with cinobufagin-induced expression of IL-10 after activation of $\alpha 7-n A C h R s$. Furthermore, activation of $\alpha 7$ nAChR has been correlated with JAK-STAT pathway $[13,94]$. Our recent findings indicated that exogenous and endogenous IL-10 stimulated $\beta$-endorphin expression via the IL-10 receptor/JAK1/STAT3 signal pathway by the autocrine mechanism [77-79]. Thus, we postulate that cinobufagin produces mechanical antiallodynia through microglial expression of IL-10 following $\alpha 7-n A C h R$ activation and MAPK signaling, followed by expression of $\beta$-endorphin via the IL-10 receptor/JAK1/STAT3 signaling. The pathway for cinobufagin to produce mechanical antiallodynia in bone cancer pain is schematically illustrated in Fig. 9.

It has been extensively shown that activation of microglia is associated with the development of neurodestruction and nociception [3, 84, 86]. However, accumulated evidence reveals that microglia also plays an important role in neuroprotection and antinociception [21, 30, 34, 45, 77, 78]. Expressed in astrocytes and microglia, IL-10 is a known antiinflammatory and immunosuppressive cytokine and exhibits marked antinociception in neuropathic pain and inflammatory pain $[42,54,67,77,78]$. We have recently discovered that IL-10 produced antinociception through spinal microglial expression of $\beta$-endorphin [77, 78], by which activation of the GLP-1 receptor and GPR40 produced mechanical antiallodynia and thermal antihyperalgesia in a variety of rodent models of painful hypersensitivity $[52,79]$. Our current cinobufagin findings further highlight the broad significance of the recently uncovered spinal microglial IL-10/ $\beta$-endorphin pathway in the regulation of antinociception in chronic pain. 


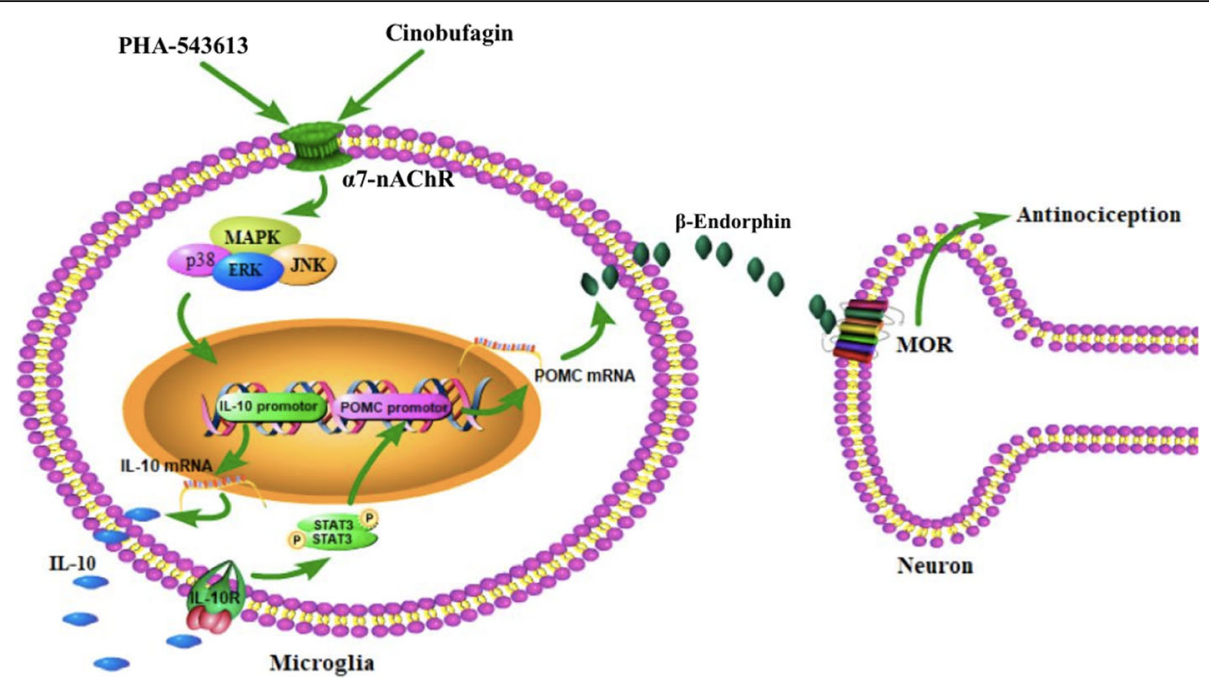

Fig. 9 Illustration of the proposed mechanisms underlying cinobufagin-mediated antinociception through stimulation of spinal microglial IL-10/ $\beta$ endorphin pathway following a7-nicotinic acetylcholine receptor (a7-nAChR) activation. Cinobufagin and PHA-543613 stimulate mitogenactivated protein kinase (MAPK) activation following agonism of the a7-nAChR and excrete IL-10, which subsequently activates the IL-10 receptor and expresses $\beta$-endorphin through an autocrine mechanism. The released $\beta$-endorphin passes the microglial neuronal synapse and activates $\mu-$ opioid receptor (MOR) in neurons to produce antinociception

\section{Conclusion}

IL-10, expressed in astrocytes and microglia, is a known antiinflammatory and immunosuppressive cytokine and exhibits marked antinociception in neuropathic pain and inflammatory pain. We have recently discovered that IL10 produced antinociception through spinal microglial expression of $\beta$-endorphin, by which activation of the GLP-1 receptor and GPR40 produced mechanical antiallodynia and thermal antihyperalgesia in a variety of rodent models of painful hypersensitivity. In this study, we postulate that cinobufagin produces mechanical antiallodynia through microglial expression of IL-10 after $\alpha 7$-nAChR activation and MAPK signaling, followed by expression of $\beta$-endorphin. Our cinobufagin findings further highlight the broad significance of the recently uncovered spinal microglial IL-10/ $\beta$-endorphin pathway in the regulation of antinociception in chronic pain.

\section{Abbreviations}

IL: Interleukin; TNF: Tumor necrosis factor; a7-nAChR: a7-nicotinic acetylcholine receptor; CRF: Corticotropin-releasing factor; GLP-1: Glucagonlike peptide-1; POMC: Proopiomelanocortin; PDYN: Prodynorphin; MAPK: Mitogen-activated protein kinase; ERK1/2: Extracellular signal-related kinase 1/2; JNK: c-Jun N-terminal kinase; MPE: Maximal possible effect

\section{Acknowledgements}

Not applicable

\section{Authors' contributions}

$Y X W, E A$, and $X Y L$ conceived and designed the experiments. EA, UA, WZ, $H Y W, K A A$, and XFM performed the experiments. EA and YXW analyzed the data. YXW, EA, and XYL wrote the paper. All authors read and approved the final manuscript.

\section{Funding}

This study was supported by the National Natural Science Foundation of China (No. 81673403) and the Shanghai Industrial Translational Project (No. 15401901300)

\section{Availability of data and materials}

All data supporting the conclusion of the article are included in this article,

\section{Ethics approval}

All animal experimental protocols and procedures in this study were reviewed and approved by the Animal Care and Welfare Committee of Shanghai Jiao Tong University and conducted in accordance with the animal care guidelines of the National Institutes of Health.

\section{Consent for publication}

Not applicable

\section{Competing interests}

The authors declare that they have no competing interests.

Received: 25 July 2019 Accepted: 9 October 2019

Published online: 29 February 2020

\section{References}

1. AlSharari SD, Freitas K, Damaj MI. Functional role of alpha7 nicotinic receptor in chronic neuropathic and inflammatory pain: studies in transgenic mice. Biochem Pharmacol. 2013;86(8):1201-7. https://doi.org/10. 1016/j.bcp.2013.06.018

2. Baek SH, Kim C, Lee JH, Nam D, Lee J, Lee S-G, Ahn KS. Cinobufagin exerts anti-proliferative and pro-apoptotic effects through the modulation ROSmediated MAPKs signaling pathway. Immunopharmacol Immunotoxicol. 2015;37(3):265-73. https://doi.org/10.3109/08923973.2015.1027916.

3. Berta T, Qadri Y, Chen G, Ji R. Microglial signaling in chronic pain with a special focus on caspase 6, p38 MAP kinase, and sex dependence. J Dent Res. 2016;95(10):1124-31. https://doi.org/10.1177/0022034516653604.

4. Bick RJ, Poindexter BJ, Sweney RR, Dasgupta A. Effects of Chan Su, a traditional Chinese medicine, on the calcium transients of isolated cardiomyocytes: cardiotoxicity due to more than $\mathrm{Na}$, K-ATPase blocking. Life Sci. 2002;72(6):699-709. https://doi.org/10.1016/s0024-3205(02)02302-0. 
5. Boscia F, Begum G, Pignataro G, Sirabella R, Cuomo O, Casamassa A, Annunziato L. Glial $\mathrm{Na}+$ dependent ion transporters in pathophysiological conditions. Glia. 2016;64(10):1677-97. https://doi.org/10.1002/glia.23030.

6. Bristow LJ, Easton AE, Li Y-W, Sivarao DV, Lidge R, Jones KM, et al. The novel, nicotinic alpha7 receptor partial agonist, BMS-933043, improves cognition and sensory processing in preclinical models of schizophrenia. PloS One. 2016;11(7):e0159996. https://doi.org/10.1371/journal.pone. 0159996.

7. Chanteux H, Guisset AC, Pilette C, Sibille Y. LPS induces IL-10 production by human alveolar macrophages via MAPKinases-and Sp1dependent mechanisms. Respir Res. 2007:8(1):71. https://doi.org/10.1186/ 1465-9921-8-71

8. Chen S-J, Yang J-F, Kong F-P, Ren J-L, Hao K, Li M, et al. Overactivation of corticotropin-releasing factor receptor type 1 and aquaporin-4 by hypoxia induces cerebral edema. Proc Natl Acad Sci U S A. 2014;111(36):13199-204. https://doi.org/10.1073/pnas.1404493111.

9. Chen T, Hu W, He H, Gong Z, Wang J, Yu X, Zhan L. A study on the mechanism of cinobufagin in the treatment of paw cancer pain by modulating local $\beta$-endorphin expression in vivo. Evid Based Complement Alternat Med. 2013;2013:851256. https://doi.org/10.1155/2013/851256.

10. Chen T, Yuan S, Wan X-N, Zhan L, Yu X-Q, Zeng J-H, et al. Chinese herb cinobufagin-reduced cancer pain is associated with increased peripheral opioids by invaded CD3/4/8 lymphocytes. Oncotarget. 2017;8(7):11425-41. https://doi.org/10.18632/oncotarget.14005.

11. Cruz Jdos S, Matsuda H. Arenobufagin, a compound in toad venom, blocks $\mathrm{Na}(+)-K+$ pump current in cardiac myocytes. Eur J Pharmacol. 1993;239(1-3): 223-6. https://doi.org/10.1016/0014-2999(93)90999-x.

12. Dai G, Zheng D, Guo W, Yang J, Cheng A-Y. Cinobufagin induces apoptosis in osteosarcoma cells via the mitochondria-mediated apoptotic pathway. Cell Physiol Biochem. 2018;46(3):1134-47. https://doi.org/10.1159/000488842.

13. De Jonge $W, U$ Ulloa $L$. The alpha7 nicotinic acetylcholine receptor as a pharmacological target for inflammation. Br J Pharmacol. 2007;151(7):91529. https://doi.org/10.1038/sj.bjp.0707264.

14. De Simone R, Aimone-Cat MA, Carnevale D, Minghetti L. Activation of a7 nicotinic acetylcholine receptor by nicotine selectively up-regulates cyclooxygenase-2 and prostaglandin E 2 in rat microglial cultures. J Neuroinflammation. 2005;2:4. https://doi.org/10.1186/1742-2094-2-4.

15. de Vasconcelos DIB, Leite JA, Carneiro LT, Piuvezam MR, de Lima MRV, de Morais $L C L$, Rodrigues-Mascarenhas S. Anti-inflammatory and antinociceptive activity of ouabain in mice. Mediators Inflamm. 2011;2011: 912925. https://doi.org/10.1155/2011/912925

16. Niu T, Zhao L, Lin X, Cai Y, Chen S, Wang M, Qin G. Cinobufagin, a bufadienolide from traditional Chinese medicine Bufo bufo gargarizans CANTOR, inhibits PC3 cell growth in vitro and in vivo. Journal of Traditional Chinese Medical Sciences. 2019;6(2):175-83. https://doi.org/10.1016/j.jtcms.2019.03.005.

17. Fedorova OV, Bagrov AY. Inhibition of $\mathrm{Na} / \mathrm{K}$ ATPase from rat aorta by two $\mathrm{Na} / \mathrm{K}$ pump inhibitors, ouabain and marinobufagenin: evidence of interaction with different a-subunit isoforms. Am J Hypertens. 1997;10(8): 929-35. https://doi.org/10.1016/s0895-7061(97)00096-4.

18. Fedorova OV, Dorofeeva NA, Lopatin DA, Lakatta EG, Bagrov AY. Phorbol diacetate potentiates $\mathrm{Na}+-\mathrm{K}+$ ATPase inhibition by a putative endogenous ligand, marinobufagenin. Hypertension. 2002;39:298-302.

19. Fillingim RB, King CD, Ribeiro-Dasilva MC, Rahim-Williams B, Riley JL 3rd. Sex gender, and pain: a review of recent clinical and experimental findings. $J$ Pain. 2009;10(5):447-85. https://doi.org/10.1016/j.jpain.2008.12.001.

20. Forshammar J, Block L, Lundborg C, Biber B, Hansson E. Naloxone and ouabain in ultralow concentrations restore $\mathrm{Na}+/ \mathrm{K}+-\mathrm{ATPase}$ and cytoskeleton in lipopolysaccharide-treated astrocytes. J Biol Chem. 2011; 286(36):31586-97. https://doi.org/10.1074/jbc. M111.247767.

21. Gong N, Xiao Q, Zhu B, Zhang C-Y, Wang Y-C, Fan H, et al. Activation of spinal glucagon-like peptide-1 receptors specifically suppresses pain hypersensitivity. J Neurosci. 2014;34(15):5322-34. https://doi.org/10.1523/Jneurosci.4703-13.

22. Gong Z-P, Chen T, Deng L-R, Hu Y-Q, Yu X-Q. Clinical application progress of cinobufagin to cancer pain relief. Drugs Clin. 2010;4:23-34.

23. Gubbins EJ, Gopalakrishnan M, Li J. a7-nAChR-mediated activation of MAP kinase pathways in PC12 cells. Brain Res. 2010;1328:1-11. https://doi.org/10. 1016/j.brainres.2010.02.083.

24. Gui Q, Xu C, Zhuang L, Xia S, Chen Y, Peng P, Yu S. A new rat model of bone cancer pain produced by rat breast cancer cells implantation of the shaft of femur at the third trochanter level. Cancer Biol Ther. 2013;14(2):1939. https://doi.org/10.4161/cbt.23291.
25. Guo Dai LY, Yang J, Xia K, Zhang Z, Liu G, Gao T, Guo W. The synergistic antitumor effect of cinobufagin and cisplatin in human osteosarcoma cell line in vitro and in vivo. Oncotarget. 2017;8(49):85150-68. https://doi.org/10. 18632/oncotarget.19554.

26. Häuser W, Schug S, Furlan AD. The opioid epidemic and national guidelines for opioid therapy for chronic noncancer pain: a perspective from different continents. Pain Rep. 2017;2(3):e599. https://doi.org/10.1097/PR9. 0000000000000599

27. Hone AJ, Mclntosh JM. Nicotinic acetylcholine receptors in neuropathic and inflammatory pain. FEBS Lett. 2018;592(7):1045-62. https://doi.org/10.1002/ 1873-3468.12884.

28. Horie K, Ohashi M, Satoh Y, Sairenji T. The role of p38 mitogen-activated protein kinase in regulating interleukin-10 gene expression in Burkitt's lymphoma cell lines. Microbiol Immunol. 2007;51(1):149-61. https://doi.org/ 10.1111/j.1348-0421.2007.tb03885.x

29. Hou J, Wang L, Quan R, Fu Y, Zhang H, Feng W-H. Induction of interleukin-10 is dependent on p38 mitogen-activated protein kinase pathway in macrophages infected with porcine reproductive and respiratory syndrome virus. Virol J. 2012;9:165. https://doi.org/10.1186/ 1743-422X-9-165

30. Hu X, Li P, Guo Y, Wang H, Leak RK, Chen S, Chen J. Microglia/macrophage polarization dynamics reveal novel mechanism of injury expansion after focal cerebral ischemia. Stroke. 2012;43(11):3063-70. https://doi.org/10.1161/ Strokeaha.112.659656.

31. Huang $Q$, Mao X-F, Wu H-Y, Li T-F, Sun M-L, Liu H, Wang Y-X. Bullatine A stimulates spinal microglial dynorphin A expression to produce antihypersensitivity in a variety of rat pain models. J Neuroinflammation. 2016; 13(1):214. https://doi.org/10.1186/s12974-016-0696-2.

32. Huang $Q$, Mao X-F, Wu H-Y, Liu H, Sun M-L, Wang X, Wang Y-X. Cynandione A attenuates neuropathic pain through $p 38 \beta$ MAPK-mediated spinal microglial expression of $\beta$-endorphin. Brain Behav Immun. 2017;62:64-77. https://doi.org/10.1016/j.bbi.2017.02.005.

33. Iwaszkiewicz K, Schneider J, Hua S. Targeting peripheral opioid receptors to promote analgesic and anti-inflammatory actions. Front Pharmacol. 2013;4: 132. https://doi.org/10.3389/fphar.2013.00132.

34. Jia Y, Gong N, Li T-F, Zhu B, Wang Y-X. Peptidic exenatide and herbal catalpol mediate neuroprotection via the hippocampal GLP-1 receptor/ $\beta$ endorphin pathway. Pharmacol Res. 2015;102:276-85. https://doi.org/10. 1016/j.phrs.2015.10.008.

35. Jiazhen $W$, Jiage $Y$, Jun Z. Studies on the analgesic effect of cinobufacini injection and its mechanism. J Linyi Med College. 2000;2:1-16.

36. Jimenez-Andrade JM, Mantyh WG, Bloom AP, Ferng AS, Geffre CP, Mantyh PW. Bone cancer pain. Ann N Y Acad Sci. 2010;1198:173-81. https://doi.org/ 10.1111/j.1749-6632.2009.05429.x.

37. Kinoshita PF, Yshii LM, Orellana A, Paixão AG, Vasconcelos AR, Lima LS, et al. Alpha $2 \mathrm{Na}+, \mathrm{K}+-$ ATPase silencing induces loss of inflammatory response and ouabain protection in glial cells. Sci Rep. 2017;7(1):4894. https://doi.org/ 10.1038/s41598-017-05075-9

38. King JR, Gillevet TC, Kabbani N. AG protein-coupled a7 nicotinic receptor regulates signaling and TNF-a release in microglia. FEBS Open Bio. 2017;7(9): 1350-61. https://doi.org/10.1002/2211-5463.12270.

39. Krementsov DN, Thornton TM, Teuscher C, Rincon M. The emerging role of p38 mitogen-activated protein kinase in multiple sclerosis and its models. Mol Cell Biol. 2013;33(19):3728-34. https://doi.org/10.1128/MCB.00688-13.

40. Labuz D, Mousa SA, Schäfer M, Stein C, Machelska H. Relative contribution of peripheral versus central opioid receptors to antinociception. Brain Res. 2007;1160:30-8. https://doi.org/10.1016/j.brainres.2007.05.049.

41. LaCroix-Fralish ML, Mo G, Smith SB, Sotocinal SG, Ritchie J, Austin J-S, et al. The $\beta 3$ subunit of the $\mathrm{Na}+\mathrm{K}+$-ATPase mediates variable nociceptive sensitivity in the formalin test. Pain. 2009;144(3):294-302. https://doi.org/10. 1016/.jpain.2009.04.028.

42. Laughlin TM, Bethea JR, Yezierski RP, Wilcox GL. Cytokine involvement in dynorphin-induced allodynia. Pain. 2000;84(2-3):159-67.

43. Lee H-J, Koung F-P, Kwon K-R, Kang D-I, Cohen L, Yang P-Y, Yoo H-S. Comparative analysis of the bufonis venenum by using TLC, HPLC, and LCMS for different extraction methods. Aust J Pharm. 2012;15(4):52-65. https:// doi.org/10.3831/KPI.2012.15.012

44 Lendeckel U, Kähne T, Ten Have S, Bukowska A, Wolke C, Bogerts B, et al. Cathepsin $\mathrm{K}$ generates enkephalin from $\beta$-endorphin: a new mechanism with possible relevance for schizophrenia. Neurochem Int. 2009:54(7):410-7. https://doi.org/10.1016/j.neuint.2009.01.011. 
45. Li T-F, Gong N, Wang Y-X. Ester hydrolysis differentially reduces aconitine-induced anti-hypersensitivity and acute neurotoxicity: involvement of spinal microglial dynorphin expression and implications for Aconitum processing. Front Pharmacol. 2016;7:367. https://doi.org/10. 3389/fphar.2016.00367.

46. Liu BS, Cao Y, Huizinga TW, Hafler DA, Toes RE. TLR-mediated STAT 3 and ERK activation controls IL-10 secretion by human B cells. Eur J Immunol. 2014;44(7):2121-9. https://doi.org/10.1002/eji.201344341.

47. Liu C, Cao W, Chen Y, Qu D, Zhou J. Comparison of toad skins Bufo bufo gargarizans Cantor from different regions for their active constituents content and cytotoxic activity on lung carcinoma cell lines. Pharmacogn Mag. 2014;10(39):207-12. https://doi.org/10.4103/0973-1296.137358.

48. Liu M, Feng L-X, Hu L-H, Liu X, Guo D-A. Advancement in research of anti-cancer effects of toad venom (ChanSu) and perspectives. World J Tradit Chin Med. 2015;1:12-23. https://doi.org/10.15806/j.issn.2311-8571. 2014.0024.

49. Liu Q, Liu C, Jiang L, Li M, Long T, He W, Zhou J. a7 nicotinic acetylcholine receptor-mediated anti-inflammatory effect in a chronic migraine rat model via the attenuation of glial cell activation. J Pain Res. 2018;11:1129-40. https://doi.org/10.2147/JPR.S159146.

50. Lu W, Yang S. Pain relieving effects of Cinobufacini injection in 32 cases of bone cancer metastasis pain. J Guiyan College Tradit Chin Med. 2001;23(1):17.

51. Lux S, Lobos N, Lespay-Rebolledo C, Salas Huenuleo E, Kogan MJ, Flores C, Constandil $L$. The antinociceptive effect of resveratrol in bone cancer pain is inhibited by the silent information regulator 1 inhibitor selisistat. J Pharm Pharmacol. 2019;71(5):816-25. https://doi.org/10.1111/jphp.13064.

52. Mao X-F, Wu H-Y, Tang X-Q, Ali U, Liu H, Wang Y-X. Activation of GPR40 produces mechanical antiallodynia via the spinal glial interleukin-10/ $\beta$ endorphin pathway. J Neuroinflamm. 2019;16:84. https://doi.org/10.1186/ s12974-019-1457-9.

53. Mestre C, Pelissier T, Fialip J, Wilcox G, Eschalier A. A method to perform direct transcutaneous intrathecal injection in rats. J Pharmacol Toxicol Methods. 1994;32(4):197-200

54. Milligan ED, Sloane EM, Langer SJ, Hughes TS, Jekich BM, Frank MG, Cruz PE. Repeated intrathecal injections of plasmid DNA encoding interleukin-10 produce prolonged reversal of neuropathic pain. Pain. 2006;126(1-3):294308. https://doi.org/10.1016/j.pain.2006.07.009.

55. Nikodemova M, Duncan ID, Watters JJ. Minocycline exerts inhibitory effects on multiple mitogen-activated protein kinases and IKBa degradation in a stimulus-specific manner in microglia. J Neurochem. 2006;96(2):314-23. https://doi.org/10.1111/j.1471-4159.2005.03520.x.

56. Ninković J, Roy S. Role of the mu-opioid receptor in opioid modulation of immune function. Amino Acids. 2013;45(1):9-24. https://doi.org/10.1007/ s00726-011-1163-0.

57. Pieretti S, Di Giannuario A, Di Giovannandrea R, Marzoli F, Piccaro G, Minosi P, Aloisi AM. Gender differences in pain and its relief. Ann Ist Super Sanita. 2016;52(2):184-9. https://doi.org/10.4415/ANN_16_02_09.

58. Qu Y-J, Jia L, Zhang X, Wei H, Yue S-W. MAPK pathways are involved in neuropathic pain in rats with chronic compression of the dorsal root ganglion. Evidence Based Complement Altern Med. 2016. https://doi.org/10. 1155/2016/6153215.

59. Sawamura S, Obara M, Takeda K, Maze M, Hanaoka K. Corticotropinreleasing factor mediates the antinociceptive action of nitrous oxide in rats. Anesthesiology. 2003;99(3):708-15. https://doi.org/10.1097/00000542200309000-00028.

60. Seyedabadi M, Rahimian R, Ghia JE. The role of alpha7 nicotinic acetylcholine receptors in inflammatory bowel disease: involvement of different cellular pathways. Expert Opin Ther Targets. 2018;22(2):161-76. https://doi.org/10.1080/14728222.2018.1420166.

61. Shirihai O, Smith P, Hammar K, Dagan D. Microglia generate external proton and potassium ion gradients utilizing a member of the H/K ATPase family. Glia. 1998;23(4):339-48

62. Shytle RD, Mori T, Townsend K, Vendrame M, Sun N, Zeng J, Tan J. Cholinergic modulation of microglial activation by a7 nicotinic receptors. Neurochem. 2004;89(2):337-43. https://doi.org/10.1046/j.1471-4159.2004. 02347.x.

63. Sly LM, Kozicky LK, Menzies SC, Zhao ZY, Harnden K, Safari K, Turvey SE. IVlg and LPS co-stimulation induces IL-10 production by human monocytes, Which Is Compromised By An FcgammaRIIA Disease-Associated Gene Variant. Front Immunol. 2018;9:2676. https://doi.org/10.3389/fimmu.2018.02676.
64. Soares-Silva M, Diniz FF, Gomes GN, Bahia D. The mitogen-activated protein kinase (MAPK) pathway: role in immune evasion by trypanosomatids. Front Microbiol. 2016;7:183. https://doi.org/10.3389/fmicb.2016.00183.

65. Tikka TM, Koistinaho JE. Minocycline provides neuroprotection against Nmethyl-D-aspartate neurotoxicity by inhibiting microglia. J Immunol. 2001; 166(12):7527-33. https://doi.org/10.4049/jimmunol.166.12.7527.

66. Umana IC, Daniele CA, McGehee DS. Neuronal nicotinic receptors as analgesic targets: it's a winding road. Biochem Pharmacol. 2013;86(8):120814. https://doi.org/10.1016/j.bcp.2013.08.001.

67. Wagner R, Janjigian M, Myers RR. Anti-inflammatory interleukin-10 therapy in $\mathrm{CCl}$ neuropathy decreases thermal hyperalgesia, macrophage recruitment, and endoneurial TNF-a expression. Pain. 1998;74(1):35-42.

68. Wang F, Cai B, Li K-C, Hu X-Y, Lu Y-J, Wang Q, Zhang X. FXYD2, a Y subunit of $\mathrm{Na}+, \mathrm{K}+$-ATPase, maintains persistent mechanical allodynia induced by inflammation. Cell Res. 2015;25(3):318-34. https://doi.org/10. 1038/cr.2015.12.

69. Wang S, Prophete C, Soukup JM, Chen L-C, Costa M, Ghio A, Chen H. Roles of MAPK pathway activation during cytokine induction in BEAS-2B cells exposed to fine World Trade Center (WTC) dust. J Immunotoxicol. 2010;7(4): 298-307. https://doi.org/10.3109/1547691X.2010.509289.

70. Wang ZJ, Sun L, et al. Resibufogenin and cinobufagin activate central neurons through an ouabain-like action. PLoS One. 2014:9(11):e113272.

71. Wang X-L, Zhao G-H, Zhang J, Shi Q-Y, Guo W-X, Tian X-L, Song Y. Immunomodulatory effects of cinobufagin isolated from Chan Su on activation and cytokines secretion of immunocyte in vitro. J Asian Nat Prod Res. 2011;13(5):383-92. https://doi.org/10.1080/10286020.2011.565746.

72. Wang Z-J, Sun L, Heinbockel T. Resibufogenin and cinobufagin activate central neurons through an ouabain-like action. PLoS One. 2014;9(11): e113272. https://doi.org/10.1371/journal.pone.0113272.

73. Wang YX, Pang CC. Functional integrity of the central and sympathetic nervous systems is a prerequisite for pressor and tachycardic effects of diphenyleneiodonium, a novel inhibitor of nitric oxide synthase. J Pharm Exp Ther. 1993;265:263-72.

74. Wen L, Huang Y, Xie X, Huang W, Yin J, Lin W, Zeng W. Anti-inflammatory and antinociceptive activities of bufalin in rodents. Mediat Inflamm. 2014. https://doi.org/10.1155/2014/171839.

75. Whitmarsh AJ. Regulation of gene transcription by mitogen-activated protein kinase signaling pathways. Bi Biochim Biophys Acta. 2007;1773(8): 1285-98. https://doi.org/10.1016/j.bbamcr.2006.11.011.

76. Wishka DG, Walker DP, Yates KM, Reitz SC, Jia S, Myers JK, et al. Discovery of N[(3R)-1-azabicyclo[2.2.2] oct-3-yl]furo [2,3-c]pyridine-5-carboxamide, an agonist of the alpha7 nicotinic acetylcholine receptor, for the potential treatment of cognitive deficits in schizophrenia: synthesis and structure--activity relationship. J Med Chem. 2006;49:4425-36. https://doi.org/10.1021/jm0602413.

77. Wu, H.-Y., Mao, X.-F., Tang, X.-Q., Ali, U., Apryani, E., Liu, H., .Wang, Y.-X. Spinal interleukin-10 produces antinociception in neuropathy through microglial $\beta$-endorphin expression, separated from antineuroinflammation. Brain Behav Immun 2018;73:504-519. https://doi.org/10.1016/j.bbi.2018.06.015.

78. Wu H-Y, Tang X-Q, Liu H, Mao X-F, Wang Y-X. Both classic Gs-CAMP/PKA/ CREB and alternative Gs-CAMP/PKA/p38ß/CREB signal pathways mediate exenatide-stimulated expression of M2 microglial markers. J Neuroimmunol. 2018;316:17-22. https://doi.org/10.1016/j.jneuroim.2017.

79. Wu H-Y, Tang X-Q, Mao X-F, Wang Y-X. Autocrine interleukin-10 mediates glucagon-like peptide-1 receptor-induced spinal microglial $\beta$-endorphin expression. J Neurosci. 2017;37(48):11701-14. https://doi.org/10.1523/ JNEUROSCI.1799-17.2017.

80. Xie S, Spelmink L, Codemo M, Subramanian K, Pütsep K, Henriques-Normark B, Olliver M. Cinobufagin modulates human innate immune responses and triggers antibacterial activity. PLoS One. 2016;11(8):e0160734. https://doi.org/ 10.1371/journal.pone.0160734.

81. Xu L, Wang S, Shen H, Feng Q, Zhang X, Ni H, Yao M. Analgesic and toxic effects of venenum bufonis and its constituent compound cinobufagin: A comparative study. Neurotoxicol Teratol. 2019;73:49-53. https://doi.org/10. 1016/j.ntt.2019.03.004.

82. Xu L, Zhang X, Feng Q, Zheng Y, Ni H, Shen H, Yao M. Alpha-7 nicotinic receptor-targeted cinobufagin induces antinociception and inhibits NF-kB signaling pathway in DRG neurons. ACS Chem Neurosci. 2019;10(1):497-506. https://doi.org/10.1021/acschemneuro.8b00369.

83. Yamada M, Ichinose $M$. The cholinergic pathways in inflammation: a potential pharmacotherapeutic target for COPD. Front Pharmacol. 2018;9. https://doi.org/10.3389/fphar.2018.01426. 
84. Yang Q, Zhou X, Zhang M, Bi L, Miao S, Cao W, Li Y. (2015). Angel of human health: current research updates in toad medicine. Am J Transl Res. 2015;7(1):1-14.

85. Yang WN, Ma KG, Chen XL, Shi LL, Bu G, Hu XD, Qian Y-H. Mitogen-activated protein kinase signaling pathways are involved in regulating a7 nicotinic acetylcholine receptor-mediated amyloid- $\beta$ uptake in SH-SY5Y. Neuroscience. 2014;278:276-90. https://doi.org/10.1016/.neuroscience.2014.08.013.

86. Yang Y, Li H, Li T-T, Luo H, Gu X-Y, Lü N, Zhang Y-Q. Delayed activation of spinal microglia contributes to the maintenance of bone cancer pain in female Wistar rats via P2X7 receptor and IL-18. J Neurosci. 2015;35(20):795063. https://doi.org/10.1523/JNEUROSCI.5250-14.2015.

87. Yang Z, Luo $\mathrm{H}$, Wang $\mathrm{H}$, Hou $\mathrm{H}$. Preparative isolation of bufalin and cinobufagin from Chinese traditional medicine ChanSu. J Chromatogr Sci. 2008:46(1):81-5. https://doi.org/10.1093/chromsci/46.1.81

88. Yates $\mathrm{N}$, McDougall J. Effects of direct renal arterial infusion of bufalin and ouabain in conscious sheep. Br J Pharmacol. 1993;108(3):627-30.

89. Zappettini $\mathrm{S}$, et al. Pre-synaptic nicotinic receptors evoke endogenous glutamate and aspartate release from hippocampal synaptosomes by way of distinct coupling mechanisms. Br J Pharmacol. 2010;161(5):1161-71. https://doi.org/10.1111/j.1476-5381.2010.00958.x.

90. Zeng W, Dohi S, Shimonaka H, Asano T. Spinal antinociceptive action of $\mathrm{Na}+-\mathrm{K}+$ pump inhibitor ouabain and its interaction with morphine and lidocaine in rats. Anesthesiology. 1999:90(2):500-8. https://doi.org/10.1097/ 00000542-199902000-00026.

91. Zhang G, Wang C, Sun M, Li J, Wang B, Jin C, Nguyen LL. Cinobufagin inhibits tumor growth by inducing intrinsic apoptosis through AKT signaling pathway in human nonsmall cell lung cancer cells. Oncotarget. 2016;7(20):28935-46. https://doi.org/10.18632/oncotarget.7898.

92. Zhang W, Liu Y, Hou B, Gu X, Ma Z. Activation of spinal alpha-7 nicotinic acetylcholine receptor attenuates remifentanil-induced postoperative hyperalgesia. Int J Clin Exp Med. 2015;8(2):1871-9.

93. Zhang $\mathrm{H}$, Nei H, Dougherty PM. A p38 mitogen-activated protein kinasedependent mechanism of disinhibition in spinal synaptic transmission induced by tumor necrosis factor-a. J Neurosci. 2010;30(38):12844-55. https://doi.org/10.1523/JNEUROSCI.2437-10.2010.

94. Zhang Q, Lu Y, Bian H, Guo L, Zhu H. Activation of the a7 nicotinic receptor promotes lipopolysaccharide-induced conversion of M1 microglia to M2. Am J Transl Res. 2017;9(3):971-85.

\section{Publisher's Note}

Springer Nature remains neutral with regard to jurisdictional claims in published maps and institutional affiliations.

Ready to submit your research? Choose BMC and benefit from:

- fast, convenient online submission

- thorough peer review by experienced researchers in your field

- rapid publication on acceptance

- support for research data, including large and complex data types

- gold Open Access which fosters wider collaboration and increased citations

- maximum visibility for your research: over $100 \mathrm{M}$ website views per year

At $\mathrm{BMC}$, research is always in progress.

Learn more biomedcentral.com/submissions 